\title{
TNFAIP8 promotes prostate cancer cell survival by inducing autophagy
}

\author{
Suryakant Niture ${ }^{1,2}$, Malathi Ramalinga2, Habib Kedir ${ }^{1,2}$, Dorrelyn Patacsil' ${ }^{2}$, Samiksha \\ S. Niture ${ }^{3}$, James Li ${ }^{4}$, Haresh Mani ${ }^{5}$, Simeng Suy ${ }^{4}$, Sean Collins ${ }^{4}$ and Deepak Kumar ${ }^{1,2,4}$ \\ ${ }^{1}$ Julius L. Chambers Biomedical Biotechnology Research Institute, North Carolina Central University Durham, 27707 NC, USA \\ ${ }^{2}$ Cancer Research Laboratory, University of the District of Columbia, Washington, 20008 DC, USA \\ ${ }^{3}$ Catonsville High School, Catonsville, 21228 MD, USA \\ ${ }^{4}$ Lombardi Comprehensive Cancer Center, Georgetown University, Washington, 20008 DC, USA \\ ${ }^{5}$ Department of Pathology, Inova Fairfax Hospital, Falls Church, 22042 VA, USA \\ Correspondence to: Deepak Kumar, email: dkumar@nccu.edu
}

Keywords: TNFAIP8; autophagy; cell survival; prostate cancer; neuroendocrine differentiation

Received: March 14, $2018 \quad$ Accepted: May 03, $2018 \quad$ Published: June 01, 2018

Copyright: Niture et al. This is an open-access article distributed under the terms of the Creative Commons Attribution License 3.0 (CC BY 3.0), which permits unrestricted use, distribution, and reproduction in any medium, provided the original author and source are credited.

\section{ABSTRACT}

Tumor necrosis factor-a-inducible protein 8 (TNFAIP8) is a TNF-a inducible anti-apoptotic protein with multiple roles in tumor growth and survival. Mechanisms of cell survival by TNFAIP8 remain elusive. We investigated the role of TNFAIP8 in the regulation of the cell cycle, autophagy, cell survival and neuroendocrine differentiation in prostate cancer cells. We showed that TNFAIP8 dysregulates cellcycle-related proteins, in PC3 cells. Oncogenic cell survival, drug resistance and dysregulation of cell cycle-related proteins are often associated with autophagy. We demonstrated that TNFAIP8 induces autophagy by increasing expression of autophagy effectors such as LC3 $\beta$ I/II, Beclin1, 4EBP1, p62, and SIRT1. We also demonstrated that TNFAIP8 interacts with autophagy-related protein 3 (ATG3). TNFa treatment increased the expression of TNFAIP8, which was associated with increased autophagy and decreased apoptosis. We also observed an increase in expression of neuroendocrine differentiation markers, synaptophysin and chromogranin A, and drug resistance to anticancer drugs, docetaxel and doxorubicin, in cells transfected with TNFAIP8. Collectively, our findings reveal that by the creation of cellular autophagy events, TNFAIP8 promotes cell survival and drug resistance in prostate cancer cells.

\section{INTRODUCTION}

Tumor necrosis factor $\alpha$-inducible protein 8 (TNFAIP8; also known as SCC-S2, GG2-1, and NDED) is a TNF $\alpha$ inducible protein. TNFAIP8 family proteins were initially identified by comparing two matched primary and metastatic head and neck squamous cell carcinoma cell lines [1] and by investigating a TNF $\alpha$ inducible gene in endothelial cells [2]. The TNFAIP8 family includes TNFAIP8, TNFAIP8-like protein 1 (TIPE1), TNFAIP8-like protein 2 (TIPE2), and TNFAIP8-like protein 3 (TIPE3) proteins [3-5]. Several isoforms of TNFAIP8 have been identified which are involved in various physiological processes and diseases, including cancer [5-7]. TNFAIP8 is induced by NF$\mathrm{kB}$, inhibits cellular apoptosis, acts as an oncogenic molecule, and promotes cell growth/proliferation in human cancers [6, 8-11].

TNFAIP8 contains a death effector domain, which negatively regulates apoptosis in several types of cancer [4]. Depletion of TNFAIP8 in tumor cells has been shown to increase expression of genes associated with proliferation suppression, apoptosis, and fatty-acid oxidation genes and to decrease expression of several 
oncogenes [12]. TNFAIP8 v2 can promote cancer by broadly repressing p53 function [13]. Silencing of TNFAIP8 v2 in cancer cells induces p53-independent inhibition of DNA synthesis and widespread p53 binding. TNFAIP8 v2 silencing also upregulates target genes, initiates p53-dependent cell-cycle arrest, and sensitizes cells to DNA damage [13]. These studies suggest that TNFAIP8 negatively regulates apoptosis and promotes cell growth.

Recently, Sun, et al. [14] showed that TNFAIP8deficient mice had increased colitis severity compared with wild-type mice due to the lack of TNFAIP8 expression in non-hemopoietic cells. Furthermore, intestinal epithelial cells from TNFAIP8-deficient mice had higher cell-death rates and decreased proliferation compared with those from wild-type mice. TNFAIP8 inhibits Ras-related C3 botulinum toxin substrate 1 (RAC1), which regulates bacterial Listeria monocytogenes infections by controlling pathogen invasion and host-cell apoptosis [15]. In that study, TNFAIP8-knockout mice were resistant to lethal $L$. monocytogenes infection and had a decreased bacterial load in the liver and spleen [15]. In Drosophila, a lossof-function mutation in the TNFAIP8 homolog CG4091/ Sigmar led to abnormal salivary glands that have defects in the tubulin network and decreased autophagic flux [16]. The study also showed the interactions between Sigmar and several cytoskeletal proteins and the kinase Misshapen, which activate autophagy, both directly and indirectly [16]. Ha et al. [17] demonstrated that TNFAIP8 protein expression was induced by oxidative stress. Moreover, under stress conditions, TNFAIP8 interacts with F-Box and WD repeat domain containing 5 (FBXW5) to activate tubular sclerosis complex 2 (TSC2), a negative regulator of $\mathrm{mTOR}$ and a modulator of autophagy.

In this study, we investigated the role of TNFAIP8 in the regulation of cell-cycle-related proteins and autophagy in prostate and breast cancer cells. We demonstrated that alteration of TNFAIP8 in prostate cancer cells dysregulates cell-cycle-related genes (e.g., cyclin-dependent kinases [CDKs], cyclins, proliferating cell nuclear antigen [PCNA]), and autophagy markers and effectors (e.g., microtubule-associated protein 1A/1B-light chain 3 beta [LC3 3$]$ I/II, Beclin1, eukaryotic translation initiation factor 4E-binding protein 1 [4E-BP1], p62, sirtuin 1 [SIRT1]). In addition, by activation of autophagy, TNFAIP8 modulates the expression of neuroendocrine differentiation protein markers in prostate cancer cells. Ectopic expression of TNFAIP8 in cancer cells imparts resistance to TNF- $\alpha-$ induced apoptosis, which was associated with increased autophagy. These data suggest that TNFAIP8 promotes cell survival and drug resistance in prostate cancer cells by the induction of autophagy.

\section{RESULTS}

\section{Analysis of TNFAIP8 expression in cancer cells}

The expression pattern of the various TNFAIP8 isoforms in cancer cells has not been previously investigated. A previous amino-acid sequence alignment of the five reported TNFIP8 isoforms showed the N-terminal region had slight variations in their sequences and the C-terminal region was highly conserved (Figure 1A). We performed nucleotide sequence alignments of five reported TNFAIP8 transcript variants/isoforms (NCBI reference sequence: isoform 1- NM_014350.3, isoform 2NM_001077654.2, isoform 3-NM_001286813.1, isoform 4- NM_001286814.1, and isoform 5- NM_001286815.1) and designed a unique forward primer for each isoform that annealed upstream of the translation initiation codon and a universal reverse primer from highly conserved coding region (Supplementary Figure 1A, left panel). The translation of isoforms 1 and 3 yields the same TNFAIP8 amino-acid sequence, but the $5^{\prime}$ upstream regions of these isoforms vary highly from one another. Isoform RNA expression was analyzed using RT-PCR in prostate (PC3, LNCaP), breast (MDA-MB-468), and mouse Lewis Lung Cancer 1 (LLC1) cells (Figure 1B). TNFAIP8 isoform 2 RNA was expressed in both prostate cancer cell lines and MDA-MB-468 cells but not in LLC1 cells. Isoform 1 RNA was observed in PC3 and MDA-MB-468 cells but not LNCaP or LLC1 cells. TNFAIP8 isoform 5 RNA was expressed at low levels in PC3 and LNCaP cells (Figure 1B). TNFAIP8 isoform RNA expression was also evaluated in THP-1 human monocytic leukemia cells and SH-SY5Y human neuroblastoma cells using RT-PCR (Supplementary Figure 1B, right panel). THP-1 cells expressed TNFAIP8 isoform 1, 2, and 5 RNA, whereas SH-SY5Y cells had no detectable expression of any TNFAIP8 isoform RNA. RNA expression of isoform 4 was not detected in any evaluated cell line. The expression of TNFAIP8 isoform RNA was validated by sequencing the gel bands.

The protein expression of TNFAIP8 isoforms was analyzed in PC3, LNCaP, MDA-MB-468, and LLC1 cells and human liver cancer cells (HepG2) by immunoblotting (Figure 1C). Consistent with the RT-PCR data, PC3 cells expressed high levels of isoform 1 and 2 proteins (molecular weight, approximately $23 \mathrm{kDa}$ and $21 \mathrm{kDa}$, respectively) and low levels of isoform 5 protein (approximately $18 \mathrm{kDa}$ ). LNCaP cells expressed high levels of isoform 2 protein and low levels of isoform 5 protein, whereas LLC1 cells had no detectable expression of any TNFAIP8 isoform protein (Figure 1C). Interestingly, MDA-MB-468 cells only expressed isoform 1 protein, whereas HepG2 cells only expressed TNFAIP8 isoform 2 (Figure 1C). Because TNFAIP8 is a TNF $\alpha$-inducible protein [12], we confirmed the expression and identity of TNFAIP8 isoforms by 
treating three prostate cancer cell lines (PC3, LNCaP, and C4-2) with TNF $\alpha$ and analyzing the induction of TNFAIP8 isoform proteins. Treatment with TNF $\alpha(10 \mathrm{ng} / \mathrm{ml})$ induced a time-dependent increase in TNFAIP8 isoform protein expression in PC3, LNCaP, and C4-2 cells (Figure 1D). The $\mathrm{TNF} \alpha$-induced expression of TNFAIP8 isoforms in all three cell lines increased modestly after $15 \mathrm{~h}$ (Figure 1D).

To confirm the expression and specificity of TNFAIP8 isoforms, without induction of TNFAIP8 by TNF $\alpha$, we knocked down TNFAIP8 protein expression in PC3 cells using siRNA (Figure 1E). Transfection of the TNFAIP8 siRNA reduced TNFAIP8 protein levels by 80-90\% compared with control-siRNA-transfected cells. Collectively, these results clearly showed that TNFAIP8 isoforms expression is highly variable between different cancer cell lines.

A

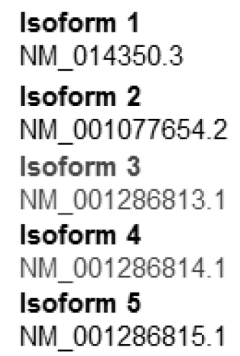

$\mathbf{B}$

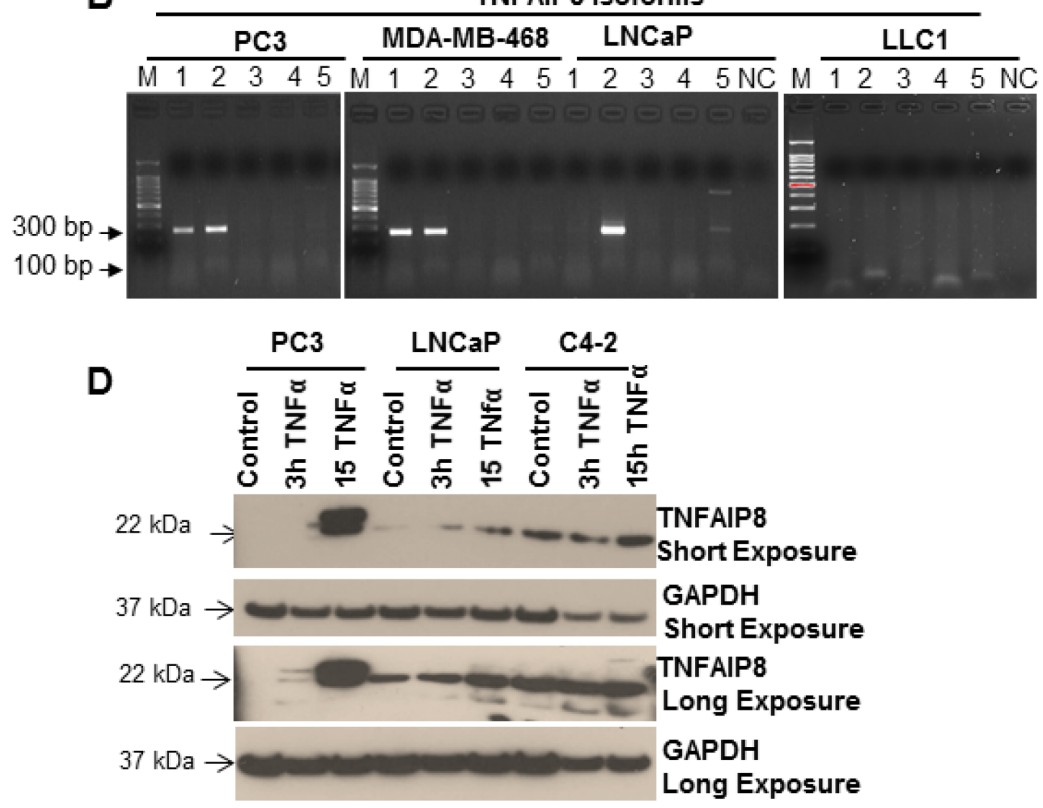

\section{TNFAIP8 promotes prostate cancer cell survival}

Because TNFAIP8 has been reported to have anti-apoptotic properties $[6,12]$, we confirmed the antiapoptotic role of TNFAIP8 in prostate cancer cells. We transiently expressed TNFAIP8-Myc-tagged protein in PC3 cells and confirmed TNFAIP8-Myc protein expression by separately immunoblotting the lysates with anti-Myc-tagged and anti-TNFAIP8 antibodies (Figure 2A). TNFAIP8-Myc protein was expressed in PC3 cells transfected with the TNFAIP8-Myc plasmid and not those transfected with empty vector based on the dual detection of the same band in the immunoblots (Figure 2A). The blot with anti-TNFAIP8 antibody demonstrated that this antibody cross-reacts with TNFAIP8-Myc protein (referred to hereafter as TNFAIP8)

Figure 1: Analysis of the expression of TNFAIP8 isoforms in cancer cell lines. (A) Amino acid sequence alignment of the five protein isoforms of human TNFAIP8. The $\mathrm{N}$-terminal region is variable, whereas the C-terminal region is highly conserved. (B) Total RNA from PC3, MDA-MB-468, LNCaP, and LLC1 cells were isolated and the expression of the five TNFAIP8 isoforms was analyzed using RTPCR. PCR products were electrophoresed on a $1.5 \%$ agarose gel and stained with ethidium bromide. NC, negative control (no cDNA); M, markers. (C) Expression of TNFAIP8 protein isoforms in various types of cancer cell lines was analyzed by immunoblotting. Cell extracts $(50 \mu \mathrm{g})$ were electrophoresed using SDS-PAGE and immunoblotted with anti-TNFAIP8 and anti- $\beta$-actin antibodies. (D) PC3, LNCaP, and C4-2 cells were cultured for $24 \mathrm{~h}$ and treated with TNF $\alpha(10 \mathrm{ng} / \mathrm{ml})$ for $3 \mathrm{~h}$ and $15 \mathrm{~h}$. Cell extracts $(50 \mu \mathrm{g})$ were immunoblotted with antiTNFAIP8 and anti-GAPDH antibodies. (E) PC3 cells were transfected with control siRNA or TNFAIP8 siRNA (100 nM) for 30 h. Cell extracts $(50 \mu \mathrm{g})$ were immunoblotted with anti-TNFAIP8 and anti-GAPDH antibodies. Endo-endogenous. 
in addition to endogenous TNFAIP8 isoforms (Figure 2A). To confirm the anti-apoptotic role of TNFAIP8 in prostate cancer cells, we transiently expressed TNFAIP8 protein in PC3 cells and treated them with doxorubicin. Cell lysates were then immunoblotted for the apoptotic markers for poly(ADP-ribose) polymerase (PARP) and caspase-3 (Figure 2B, left panel). TNFAIP8-transfected cells had higher levels of full-length procaspase-3 and lower levels of cleaved caspase- 3 compared with empty-vector-transfected cells (Figure 2B, left panel). Doxorubicin treatment induced cleavage of caspase- 3 and PARP proteins. However, the levels of cleaved caspase-3 and PARP decreased significantly following TNFAIP8 expression in doxorubicin-treated cells (Figure 2B, left panel). PC3 cell morphology and growth were evaluated following TNFAIP8 expression and under doxorubicin treatment conditions. TNFAIP8 expression promoted cell growth compared with empty-vector-transfected cells. Doxorubicin treatment induced cell apoptosis, but the number of apoptotic cells decreased significantly when TNFAIP8 was expressed in doxorubicin-treated cells (Figure 2B, right upper and lower panels).

We investigated the role of TNFAIP8 in cell survival using a cell colony formation assay and by measuring cell proliferation in three prostate cancer cell lines. PC3, LNCaP, and C4-2 cells were transfected with empty vector or TNFAIP8 plasmid for $24 \mathrm{~h}$, and lysates were immunoblotted with anti-Myc antibody to confirm TNFAIP8 expression (Figure 2C, upper panel). Empty-vector or TNFAIP8-Myc transfected cells were transferred to 6-well plates and allowed to grow for 7 to 10 days. Following staining, colonies were counted and plotted (Figure 2C, middle and lower panels). The percentage colony formation of PC3, LNCaP, and C4-2 cells was significantly higher in TNFAIP8-transfected cells compared with empty-vector-transfected cells (Figure 2C, middle and lower panels). Then, PC3, LNCaP, and C4-2 cells were transfected with empty vector or TNFAIP8 plasmid for $18 \mathrm{~h}$ and treated with docetaxel or doxorubicin. The relative cell proliferation was measured using a WST-1 assay. TNFAIP8 overexpression decreased the sensitivity of all prostate cancer cell lines to docetaxel or doxorubicin. Thus, TNFAIP8 promotes cell proliferation (Figure 2D, left and right panels). Based, on this observation, it seems likely that TNFAIP8 modulates sensitivity to chemotherapies and may play a role in drug resistance. Collectively, these data suggest that TNFAIP8 promotes prostate cancer growth and increased drug resistance by inhibiting cellular apoptosis.

\section{TNFAIP8 dysregulates cell-cycle regulatory proteins}

TNFAIP8 has been implicated as an oncogenic molecule that regulates cancer cell progression in various human cancers [8-10]. To determine the molecular- level mechanisms underlying these functions, we expressed TNFAIP8 protein in PC3 cells (Figure 3A, upper panel) and performed microarray profiling. We assessed the effect of TNFAIP8 on global gene expression using a cut-off $p$-value $<0.01$ and fold-change $\geq 1.5$. TNFAIP8 expression was approximately 11-fold higher in TNFAIP8-transfected cells compared with emptyvector-transfected cells. Microarray analysis revealed that several genes associated with cell cycle (e.g., checkpoint kinase 1 [CHEK1], CDK2, cell division cycle (CDC20, CDC45, CDCA4) and DNA replication or silencing (e.g., chromatin licensing and DNA replication factor 1 [CDT1], origin recognition complex subunit 6 [ORC6], minichromosome maintenance 6 [MCM6], MCM10, PCNA) were downregulated (1.5 to 1.8 -fold) in TNFAIP8Myc plasmid transfected cells compared with empty vector-transfected PC3 cells (Figure 3A, lower panel). To validate the microarray data, we performed RT/qPCR. RT/qPCR data demonstrated that the ectopic expression of TNFAIP8 gene downregulates the expression of several cell cycle-related gene transcripts including CCNB2, CDK2, CCNE2, and others (Figure 3B, upper and lower panels). In addition, we immunoblotted lysates from TNFAIP8-transfected cells and analyzed the expression of key cell-cycle regulatory proteins such as cyclins, Myt1, p21 and p27. When comparing TNFAIP8- and emptyvector-transfected PC3 cells, TNFAIP8 overexpression upregulated CHEK1, Cyclin B, and myelin transcription factor 1 (MYT1) proteins and induced phosphorylation of Histone-H3 at Ser10, CDC2 at Tyr15, and WEE1 G2 checkpoint kinase (Wee1) at Ser642 (Figure 3C, left panel). However, no changes in CDK inhibitors, such as p21 and p27, were observed (Figure 3C, right panel). These data suggest that TNFAIP8 dysregulates cellcycle-related proteins and possibly modulates cell-cycle progression.

To explore the role of TNFAIP8 in cell-cycle regulation, we expressed TNFAIP8 in PC3 and LNCaP cells and monitored cell-cycle progression using flow cytometry (Supplementary Figure 2). Cells expressing TNFAIP8 did not display any cell-cycle changes or cellcycle arrest. The data suggest that the regulation of cellcycle regulatory proteins by TNFAIP8 does not seem to directly affect the cell-cycle progression.

\section{TNFAIP8 induces autophagy}

Autophagy plays an important role both in cell survival and apoptosis, and the interplay between cellcycle proteins and autophagy has been well-documented $[18,19]$. Because TNFAIP8 is an oncogenic molecule that dysregulates the expression of multiple cell-cyclerelated proteins and promotes cancer cell growth (Figures 3, 2), and therefore we hypothesized that TNFAIP8 may promote cancer cell growth by inducing autophagy. We transfected PC3 cells with empty vector 


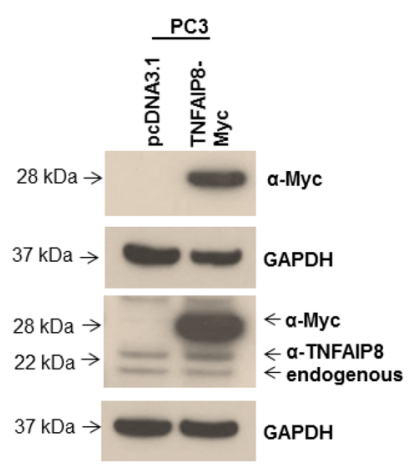

C

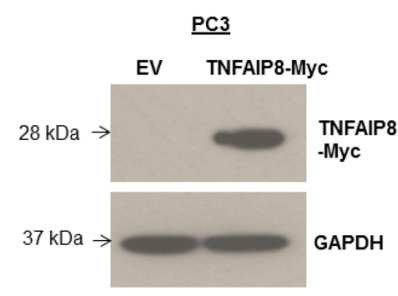

EV
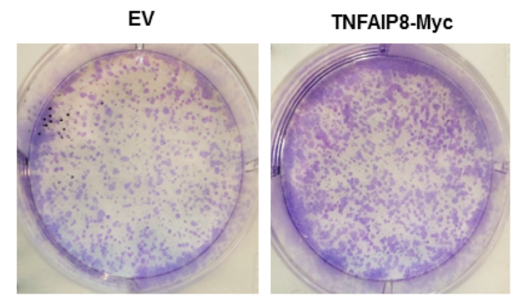

$\underline{\mathrm{PC} 3}$

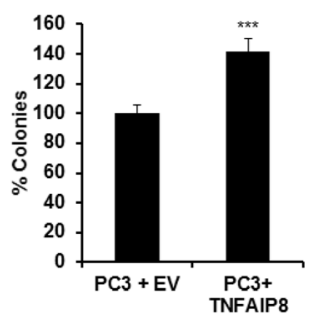

$\mathbf{B}$
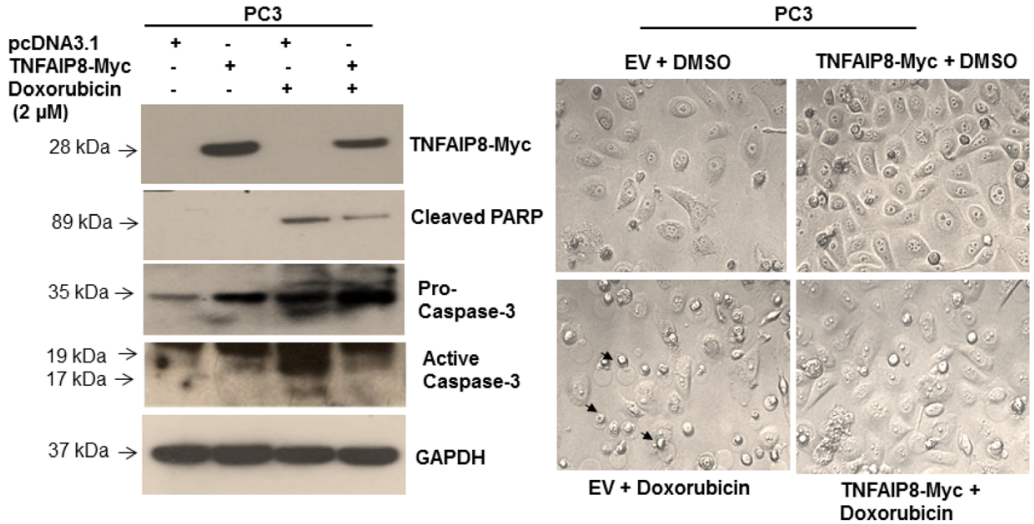

Doxorubicin
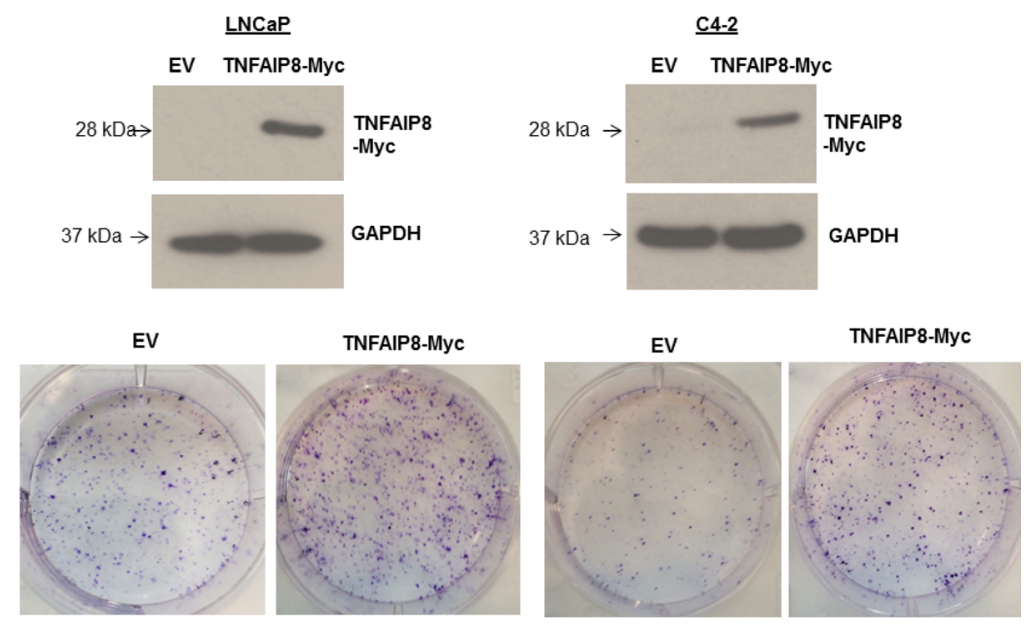

$\underline{\text { LNCaP }}$

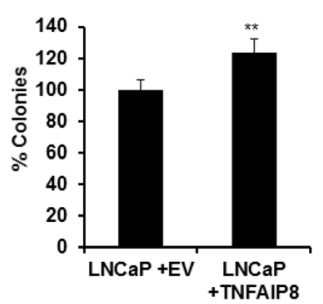

$\underline{\mathrm{C} 4-2}$

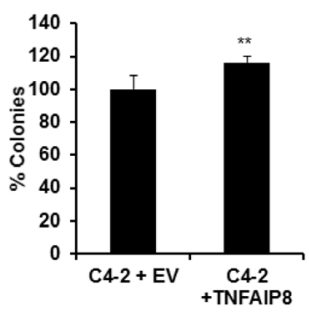

D
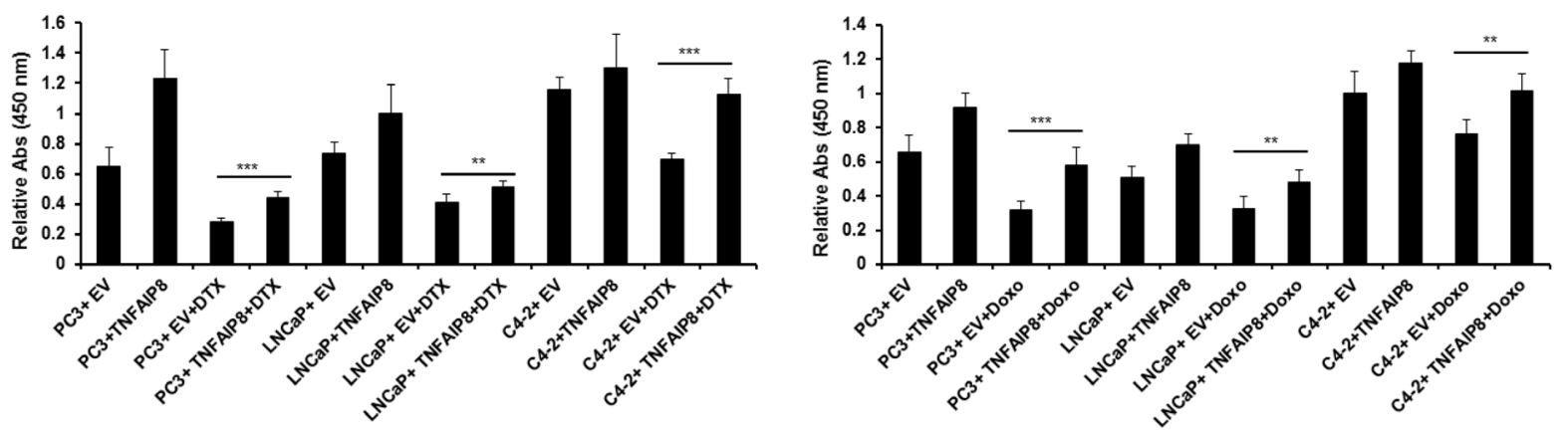

Figure 2: TNFAIP8 promotes cell colony formation and cell proliferation in prostate cancer cells. (A) PC3 cells were transfected with empty vector (EV) or TNFAIP8-Myc plasmids for $24 \mathrm{~h}$. Cell extracts $(50 \mu \mathrm{g})$ were immunoblotted with anti-Myc, antiTNFAIP8, and anti-GAPDH antibodies. (B) PC3 cells were transfected with empty vector or TNFAIP8-Myc plasmids for 24 h. Cells were treated with DMSO or $2 \mu \mathrm{M}$ doxorubicin (Doxo) for $24 \mathrm{~h}$. Cell extracts $(50 \mu \mathrm{g})$ were immunoblotted with anti-Myc, anti-cleaved PARP, anti-caspase 3, and anti-GAPDH antibodies (left panel). PC3 cells $\left(1 \times 10^{5}\right)$ were transfected with empty vector or TNFAIP8-Myc plasmid 
for $24 \mathrm{~h}$. Cells were treated with DMSO or $2 \mu \mathrm{M}$ doxorubicin for $24 \mathrm{~h}$. Cells were imaged using a Nikon light microscope (40× objective; right panel) Arrows indicate the apoptotic cells. (C) PC3, LNCaP, and C4-2 cells were transfected with empty vector or TNFAIP8-Myc plasmid for $30 \mathrm{~h}$. The expression of the TNFAIP8-Myc protein was analyzed by immunoblotting (upper panels). Transfected live cells (2000 cells/well) were re-plated in 6-well plates in triplicate and cultured at $37^{\circ} \mathrm{C}$ for 7 days. Cells were fixed, stained with crystal violet, counted, and plotted (middle and lower panels). (D) PC3, LNCaP, and C4-2 cells were transfected with the TNFAIP8-Myc plasmid or empty vector for $18 \mathrm{~h}$ and treated with DMSO or $0.5 \mathrm{nM}$ of docetaxel (DTX) or $1 \mu \mathrm{M}$ doxorubicin (Doxo) for $24 \mathrm{~h}$. Cells were trypsinized and counted. Live cells $\left(1 \times 10^{4}\right.$ cells/well $)$ were cultured for $48 \mathrm{~h}$, and cell proliferation was measured using a WST-1 assay. Data are expressed as the mean \pm S.D. ${ }^{* *} p<0.01,{ }^{* * *} p<0.001$, according to the two-tailed Student's $t$-test.

or increasing amounts of TNFAIP8 plasmid and analyzed the effect of TNFAIP8 expression on autophagy markers by Western blotting (Figure 4A). TNFAIP8 expression in PC3 cells increased the expression of LC3 $\beta$ I/II, 4E$\mathrm{BP} 1$, autophagy-related protein 3 (ATG3), and Beclin 1 in a dose-dependent manner, indicating that TNFAIP8 induces autophagy (Figure 4A). TNFAIP8 expression also stabilized p62, a protein that recognizes and facilitates the degradation of toxic biomolecules through autophagy [20]. Further, TNFAIP8 expression increased SIRT1 levels (Figure 4A). SIRT1 is a NAD-dependent deacetylase that regulates the nucleocytoplasmic translocation of LC3 $\beta$ I/II through deacetylation. This acetylation-deacetylation cycle helps to regulate autophagy [21, 22]. SIRT1 upregulation by TNFAIP8 suggests that LC3 stability and localization play a role in TNFAIP8-induced autophagy. Next, we studied the autophagy-inducing effects of TNFAIP8 using the autophagy inhibitor 3-methyladenine. PC3 cells were transfected with TNFAIP8 plasmid and treated with 3 -methyladenine for $24 \mathrm{~h}$. Then, we analyzed LC3 $\beta$ I/II expression by immunoblotting. TNFAIP8 increased the expression of LC3 $\beta$ I/II, whereas treatment of TNFAIP8transfected cells with 3-methyladenine reduced LC3 $\beta$
A
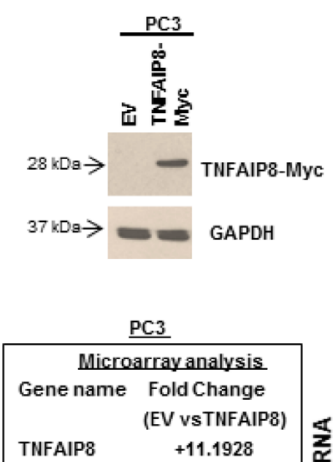

TNFAIP8

CDK2

CDC 45

CDC20

CHEK

MCM6

MCM 10

ORC6

MAD2L1

CDT1

PCNA

CCNE2

CCNB2

$\mathrm{CCNA2}$

CDKN3

CDCA4

CENPM

RFC3
B

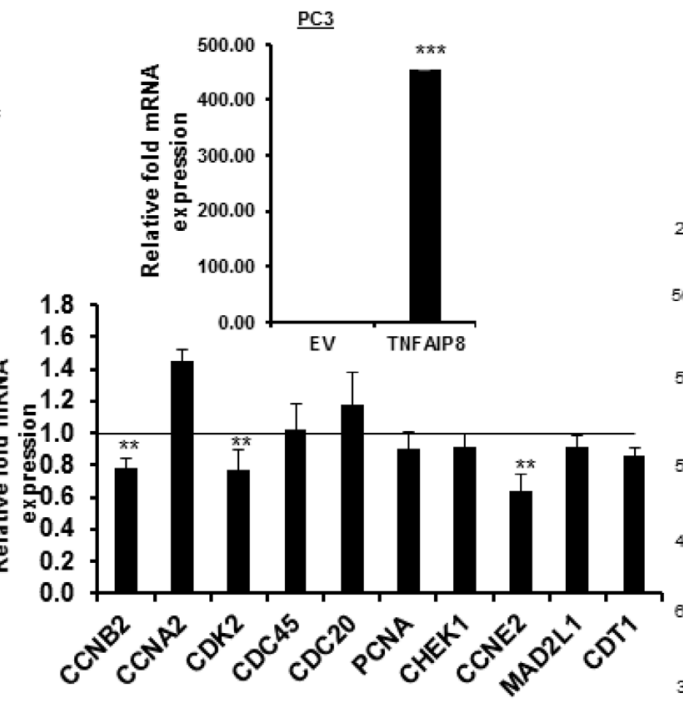

C

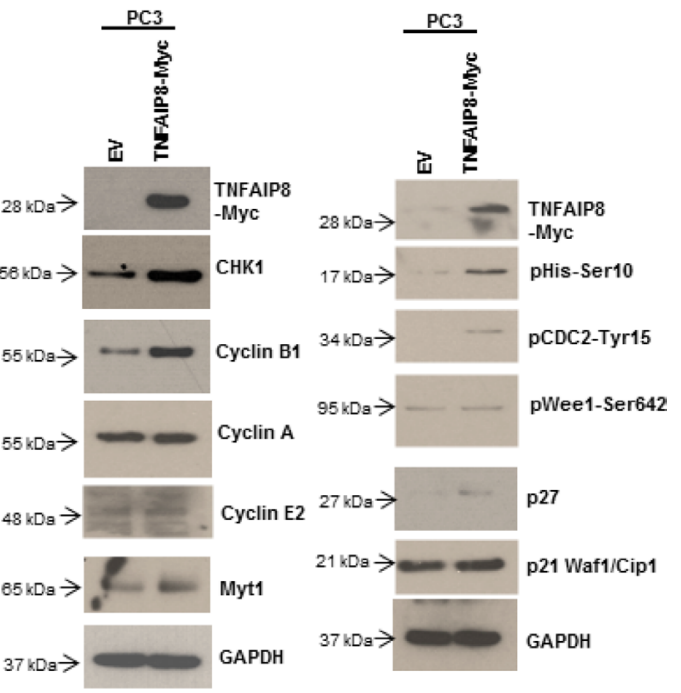

Figure 3: The effect of TNFAIP8 on the expression of cell-cycle-related proteins. (A) PC3 cells were transfected with empty vector or TNFAIP8-Myc plasmid for $30 \mathrm{~h}$. The expression of the TNFAIP8-Myc protein in cell extracts was analyzed by immunoblotting with anti-Myc and anti-GAPDH antibodies (upper panel). PC3 cells were transfected with empty vector or TNFAIP8-Myc plasmid for $30 \mathrm{~h}$, and total RNA was isolated. The effect of TNFAIP8 gene expression on the expression of different cell-cycle-related genes was analyzed using microarray (lower panel). Fold-change represents the relative gene expression changes in empty-vector- verses TNFAIP8Myc-transfected PC3 cells. (B) PC3 cells were transfected with empty vector or TNFAIP8-Myc plasmid for 30 h. The effect of expression of the TNFAIP8-Myc plasmid on the regulation of cell cycle-related genes was analyzed by RT/qPCR as described in materials and methods section. (C) PC3 cells were transfected with empty vector or TNFAIP8-Myc plasmid for 30 h. The effect of TNFAIP8 protein on the expression of cell cycle-related proteins was analyzed by immunoblotting of the cell extracts with antibodies against p21, p27, and phosphorylated Histone- H3, CDC2, and Wee1, and other indicated antibodies. Data are expressed as the mean \pm S.D. ${ }^{* *} p<0.01,{ }^{* * *} p<$ 0.001 , according to the two-tailed Student's $t$-test. 
I/II expression (Figure 4B). These data suggest that TNFAIP8 can induce cellular autophagy in PC3 cells.

\section{TNFAIP8 is essential for TNF $\alpha$-induced autophagy}

TNF $\alpha$ has been shown to increase autophagy in multiple cells [23-25]. We confirmed this observation by treating PC3 and C4-2 cells with TNF $\alpha$. LC3 $\beta$ I/II expression was enhanced in both cell lines following treatment (Figure 4C). Because TNFAIP8 is a TNF $\alpha$ inducible protein that helps protect cells from $\mathrm{TNF} \alpha-$ induced cell death [4], we hypothesized that TNFAIP8 plays a role in $\mathrm{TNF} \alpha$-induced autophagy. First, we confirmed treatment with TNF $\alpha$ induced TNFAIP8 expression and autophagy, as indicated by LC3 $\beta$ I/II. Then, we knocked down TNFAIP8 expression using siRNA, treated cells with TNF $\alpha$ to induce autophagy, and assessed autophagy by immunoblotting. TNFAIP8 knockdown significantly decreased LC3 $\beta$ I/II expression compared that of controlsiRNA-transfected cells (Figure 4D). TNFAIP8 knockdown inhibited TNF $\alpha$-induced autophagy, suggesting a critical role for TNFAIP8 in this process.

Next, we studied TNF $\alpha$-induced autophagy using immunofluorescence. When GFP-tagged LC $3 \beta$ plasmid was co-transfected with TNFAIP8 plasmid and when GFP-tagged-LC3 $\beta$-transfected cells were treated with TNF $\alpha$, GFP-LC3 $\beta$ formed puncta (Figure 4E, upper and lower panels). Treatment with 3-methyladenine reduced TNFAIP8-mediated LC3 $\beta$ puncta formation suggesting that TNFAIP8 is involved in modulating cellular autophagy.

\section{TNFAIP8 expression is associated with autophagic flux in normal and breast cancer cells}

In order to establish the broader role of TNFAIP8 in autophagy modulation, we analyzed the expression of TNFAIP8 and LC3 $\beta$ I/II in normal and breast cancer cells by immunoblotting. Breast cancer cell lines included MCF-7 MCF7-RAS, MCF7-Adriamycin resistant (ADR); normal immortalized breast cell lines included MCF10A, MCF10A-Neo, MCF10A-RAS/ErbB2 and MCF10ATGFa. MCF7-RAS, MCF10A-RAS/ErbB2, and MCF10ATGF $\alpha$ cells stably express RAS, ErbB2, and TGF $\alpha$, respectively [26-30]. TNFAIP8 expression was 2-3-fold higher in MCF10A-RAS/ErbB2 and MCF10A-TGF $\alpha$ cells than in MCF10A cells or empty-vector-transfected MCF10A cells (Supplementary Figure 3A, lanes 4-7). The higher TNFAIP8 expression in MCF10A-RAS/ErbB2 and MCF10A-TGF $\alpha$ cells induced the expression of LC3 $\beta$ II isoforms compared with MCF10A cells or empty-vectortransfected MCF10A cells (Supplementary Figure 3A, lanes 4-7). Further, we observed higher autophagic flux, as indicated by LC3 $\beta$ I/II, in MCF-10A cell lines expressing higher TNFAIP8 levels, suggesting TNFAIP8 is associated with autophagic flux. Interestingly, MCF-7, MCF7-RAS, and MCF7-ADR cells showed lower expression levels of both TNFAIP8 and LC3 $\beta$ I/II compared with MCF10A cells (Supplementary Figure 3A, lanes 1-4). Collectively, these data suggest that TNFAIP8 expression may be associated with higher autophagic flux in MCF10A breast epithelial cells compared with MCF-7 breast cancer cells.

Next, we selected the MCF-7 cells, which expressed the lowest levels of TNFAIP8 and evaluated the effect of ectopic TNFAIP8 expression with serum starvation on LC3 $\beta$ I/II expression by immunoblotting. Overexpression of TNFAIP8 in MCF-7 cells induced autophagy in both serum-starved and complete-media-grown cells at $24 \mathrm{~h}$ and $48 \mathrm{~h}$ post-transfection (Supplementary Figure 3B, left \& right panels). Collectively our results suggest that TNFAIP8 increases cellular autophagy in breast cancer cells.

\section{TNFAIP8 interacts with ATG3, induces autophagy, and reduces cellular apoptosis}

TNFAIP8 has been reported to interact with several cytoskeletal proteins, such as Act42 and alpha TUB4B in Drosophila. These proteins participate in the autophagy process, either directly or indirectly [16, 31]. A highthroughput interactome study by Kristensen et al. [32] demonstrated that TNFAIP8 interacts with ATG3. Because our data showed that TNFAIP8 modulated autophagy markers, we hypothesized that TNFAIP8 may interact with ATG3 or other autophagy-related proteins in prostate cancer cells. To determine if TNFAIP8 interacts with ATG3, we transfected PC3 cells with TNFAIP8 or empty vector (Figure 5A, input panel), immunoprecipitated cell lysates with anti-ATG3 antibody or control antibody, and analyzed interactions by immunoblotting with antiTNFAIP8 or anti-ATG3 antibody as indicated (Figure 5B). ATG3 co-immunoprecipitated with TNFAIP8 in TNFAIP8transfected cells but not empty-vector-transfected cells (Figure 5B), suggesting that TNFAIP8 increases autophagy through an interaction with ATG3 or one of the components of the autophagosome.

Next, we investigated the biological significance of TNFAIP8-induced autophagy with respect to apoptosis. PC3 cells were transfected with the TNFAIP8-Myc plasmid or empty vector and cell were treated with vehicle or TNF $\alpha$ to induce apoptosis in the presence or absence of the autophagy inhibitor 3-methyladenine. Following treatments, autophagy was detected by immunoblotting. Compared with emptyvector-transfected cells, TNFAIP8 overexpression in PC3 cells increased LC3 $\beta$ I/II expression and decreased cleaved PARP levels, indicating autophagy initiation and apoptosis inhibition, respectively (Figure 5C, lane $1 \& 2$ ). Treatment with 3-methyladenine reduced LC3 $\beta$ I/II expression and increased cleaved PARP levels significantly (Figure 5C, lane 2 vs 4) in TNFAIP8-transfected cells compared with untreated TNFAIP8-transfected cells. The combination of TNFAIP8 overexpression and TNF $\alpha$ treatment increased 

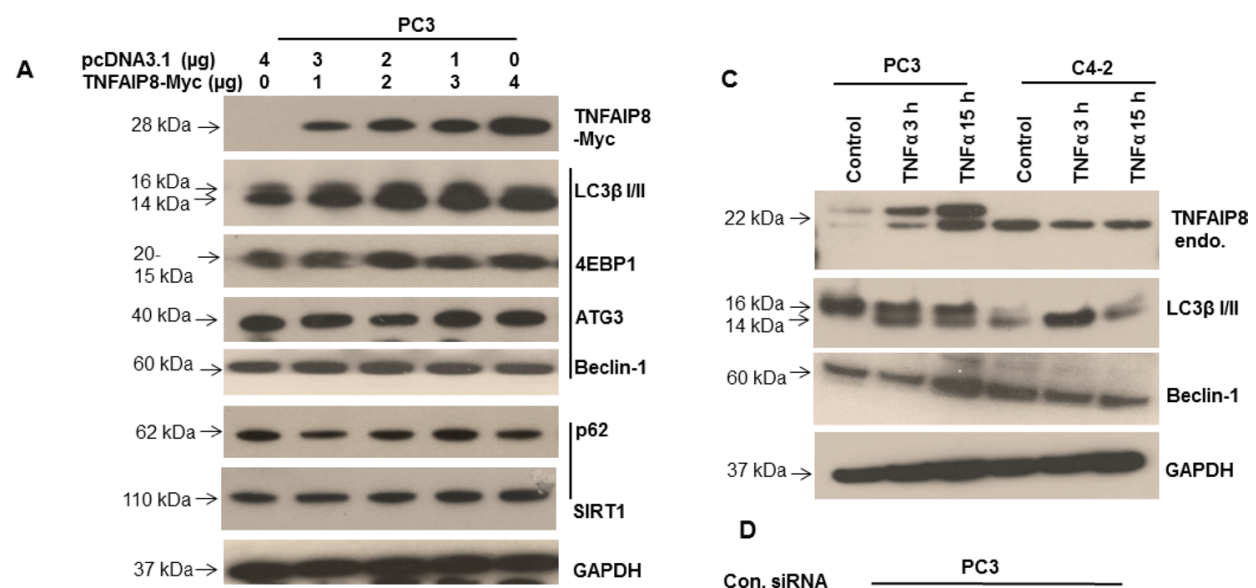

D
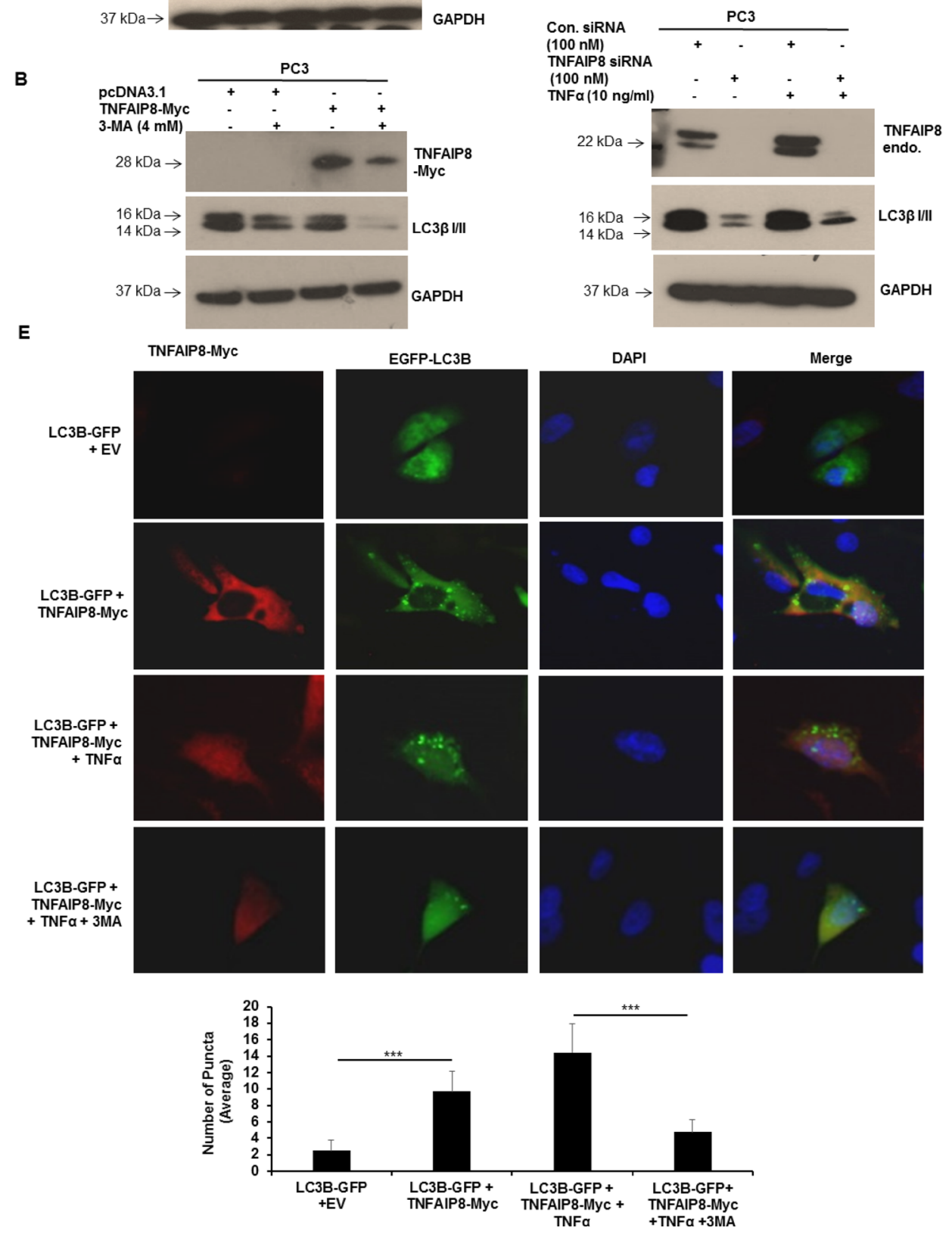

Figure 4: TNFAIP8 induces autophagy in PC3 cells. (A) PC3 cells were transfected with empty vector or increasing amounts of TNFAIP8-Myc plasmid for $30 \mathrm{~h}$. Cell extracts $(50 \mu \mathrm{g})$ were electrophoresed using SDS-PAGE and immunoblotted with anti-Myc, antiLC3 $\beta$ I/II, anti-4E-BP1, anti-ATG3, anti-Beclin 1, anti-p62, anti-SIRT1, and anti-GAPDH antibodies. (B) PC3 cells were transfected with empty vector or TNFAIP8-Myc plasmid and treated with 3-methyladenine $(4 \mathrm{mM})$ for $24 \mathrm{~h}$. Cell extracts $(50 \mu \mathrm{g})$ were immunoblotted 
with anti-Myc, anti-LC3 $\beta$ I/II, and anti-GAPDH antibodies. (C) PC3 and C4-2 cells were cultured for $24 \mathrm{~h}$ and treated with TNF $\alpha$ $(10 \mathrm{ng} / \mathrm{ml})$ for $3 \mathrm{~h}$ and $15 \mathrm{~h}$. Cell extracts $(50 \mu \mathrm{g})$ were immunoblotted with anti-TNFAIP8, anti-LC3 $\beta$ I/II, anti-Beclin-1, and anti-GAPDH antibodies. Endo-endogenous. 3-MA - 3-methyladenine. (D) PC3 cells were transfected with control siRNA or TNFAIP8 siRNA (100 nM) and treated with TNF $\alpha(10 \mathrm{ng} / \mathrm{ml})$ for $24 \mathrm{~h}$ as indicated. Cell extracts $(50 \mu \mathrm{g})$ were immunoblotted with anti-TNFAIP8, anti-LC3 $\beta$ I/II and anti-GAPDH antibodies. Endo-endogenous. (E) PC3 cells were grown on coverslips in 6-well plates for $24 \mathrm{~h}$ and co-transfected with $2 \mu \mathrm{g}$ of empty vector and GFP-tagged-LC3B plasmid or TNFAIP8-Myc plasmid and GFP-tagged LC3B plasmid. Cells were treated with 10 $\mathrm{ng} / \mathrm{ml} \mathrm{TNF} \alpha$ and $4 \mathrm{mM} \mathrm{3-methyladenine} \mathrm{for} 24 \mathrm{~h}$ as indicated. TNFAIP8 was labeled using anti-Myc antibody and an Alexa-Fluor-568conjugated secondary antibody. Nuclei were stained with DAPI. Cells were imaged using an OlympusBX60 fluorescent microscope (40× objective) (upper panels). The number of GFP-LC3B-related puncta formed in cells $(n=10)$ was counted and plotted (lower panels). Data are expressed as the mean \pm S.D. ${ }^{* * *} p<0.001$, according to the two-tailed Student's $t$-test.

LC3 $\beta$ I/II expression and reduced cleaved PARP levels significantly compared with empty-vector-transfected TNF $\alpha$ treated cells and with empty-vector-transfected TNF $\alpha$-and 3-methyladenine-treated cells (Figure 5C, lanes 5-8). These data clearly showed that TNFAIP8 expression inhibits TNF $\alpha$ mediated apoptosis by increasing autophagy in PC3 cells.

\section{TNFAIP8 is involved in the modulation of neuroendocrine differentiation markers}

Previous studies showed that activation of the autophagy signaling pathway contributes to neuroendocrine differentiation in prostate cancer cells $[33,34]$, and our results demonstrated that TNFAIP8-induced autophagy was not limited to prostate cancer cells. To determine if TNFAIP8 regulates neuroendocrine differentiation in prostate cancer cells by the activation autophagy, we transfected PC 3 cells with varying concentrations of TNFAIP8 plasmid and evaluated the expression of neuroendocrine differentiation (NED) biomarkers, such as synaptophysin, neuronspecific enolase (NSE), chromogranin A, and NCAM1/CD56 (Figure 6A). Expression of TNFAIP8 in PC3 cells increased the expression of LC3 $\beta$ I/II and the NED biomarkers chromogranin A and synaptophysin in a dosedependent manner but did not affect the expression of NSE (Figure 6A). We also tested the expression of NED biomarkers in PC3 cells that stably expressed TNFAIP8 (Figure 6B). The stable expression of TNFAIP8 in PC3 cells increased the expression of chromogranin A compared with normal PC3 cells but did not affect the expression of synaptophysin or NSE. The expression of NCAM-1/CD56 was not detected in either cell line (Figure 6A and 6B). We also examined the effects of TNFAIP8 and 3-methyladenine on the regulation of chromogranin A and synaptophysin in PC3 cells. TNFAIP8 expression induced the expression of chromogranin A and synaptophysin as well as LC3 $\beta$ I/ II in TNFAIP8-transfected cells compared with emptyvector-transfected cells (Figure 6C, lane 1\&2). Treatment with 3-methyladenine, both with and without TNFAIP8 expression, reduced the expression of chromogranin A, synaptophysin, and LC3 $\beta$ compared with untreated PC3 cells (Figure 6C, lane 3\&4), suggesting that TNFAIP8 increases NED by the activation of autophagy in PC3 cells (Figure 6C). Collectively, the data suggest that the activation of cellular autophagy by TNFAIP8 might be involved in the neuroendocrine differentiation in prostate cancer cells.

\section{DISCUSSION}

TNFAIP8 is an anti-apoptotic protein that helps inhibit TNF $\alpha$ mediated cellular apoptosis. The TNFAIP8 expression is induced following nuclear factor- $\mathrm{\kappa B}$ (NF- $\mathrm{\kappa B}$ ) activation and is controlled by various other factors. Promoter analysis of TNFAIP8 revealed potential binding sites for transcription factors, such as hypoxia-inducible factor (HIF), nuclear receptor subfamily 2 group F member 1 (NR2F1), and androgen receptor [12, 35]. TNFAIP8 expression increases significantly in various cancer cell lines, leading to cancer progression and poor prognosis $[8-10,12]$. Thus far, four TNFAIP8 protein isoforms have been reported; however, the expression levels and unique functions of each isoform are still unknown. Interestingly, all four isoforms of TNFAIP8 shared more than $90 \%$ of amino-acid sequence homology with highly conserved $\mathrm{C}$-terminal regions. In the current study, we analyzed the expression profile of TNFAIP8 isoforms in prostate, breast, and liver cancer cell lines and found that isoform 2 is the predominantly expressed isoform in prostate and liver cancer cells. RT-PCR and immunoblotting data suggested that other TNFAIP8 isoforms are also expressed in various cancer cell lines. However, the individual role of TNFAIP8 isoforms in cancer cell biology needs to be further investigated.

The TNFAIP8 protein family is involved in various functions in human diseases, including cancer $[5,6,11]$. Several studies showed that TNFAIP8 plays a role in the cellular anti-apoptotic process and promotes cellular growth and proliferation in various cancers $[6,8-11]$. However, the molecular mechanism underlying how TNFAIP8 promotes cell survival is still unknown. We investigated the role of TNFAIP8 in modulating the expression of cell-cycle-related proteins, autophagy biomarkers, and drug resistance in prostate and breast cancer cell lines. The data suggested that overexpression of TNFAIP8 reduced the expression of cell-cycle-related several proteins, such as cyclins and CDKs. However, no substantial TNFAIP8-mediated cell-cycle arrest was observed. Recent studies showed that dysregulation of cell-cycle-related protein modulates cellular autophagy 
and there is a direct interplay between cell-cycle-related proteins and autophagy modulators [18, 19]. Because autophagy plays an important role in both tumor development and cancer cell survival [36], we investigated whether TNFAIP8 is involved in cellular autophagy via dysregulation of cell-cycle-related proteins. Recently, a TNFAIP8-related proteomic analysis showed that TNFAIP8 interacts with several cytoskeletal proteins, namely Act42 and alpha Tub84B in Drosophila. These cytoskeletal proteins participate in initiating cellular autophagy, directly or indirectly $[16,31]$. Using highthroughput analysis of changes in the interactome, earlier studies showed that TNFAIP8 directly interacts with ATG3 [32], indicating TNFAIP8 may participate in the initiation of autophagy. Our data support this hypothesis; moreover, we showed that TNFAIP8 interacts with ATG3 and increases the expression of autophagy markers and effectors, such as LC3 $\beta$ I/II, Beclin1, and 4E-BP1 in PC3 cells. TNAIP8 also stabilized p62 and SIRT1, which are directly involved in controlling cellular autophagy.
A

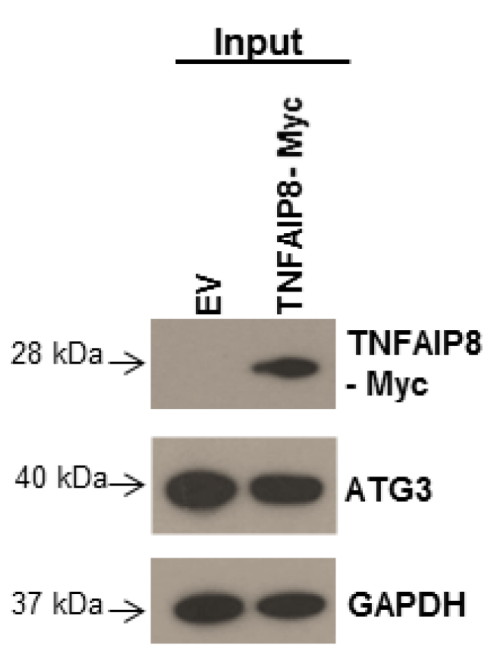

B

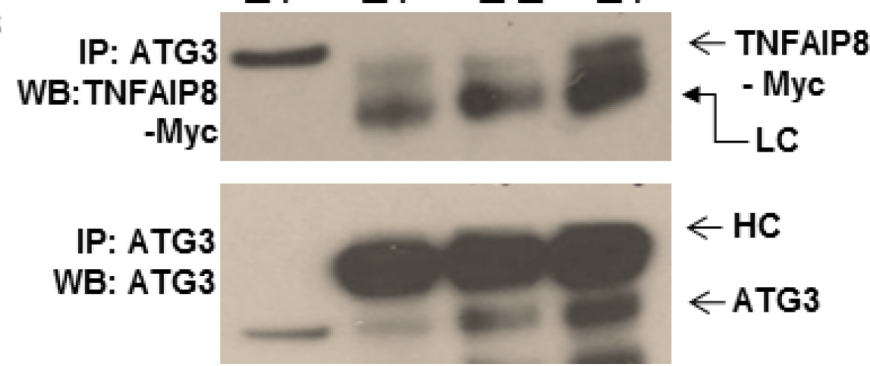

C

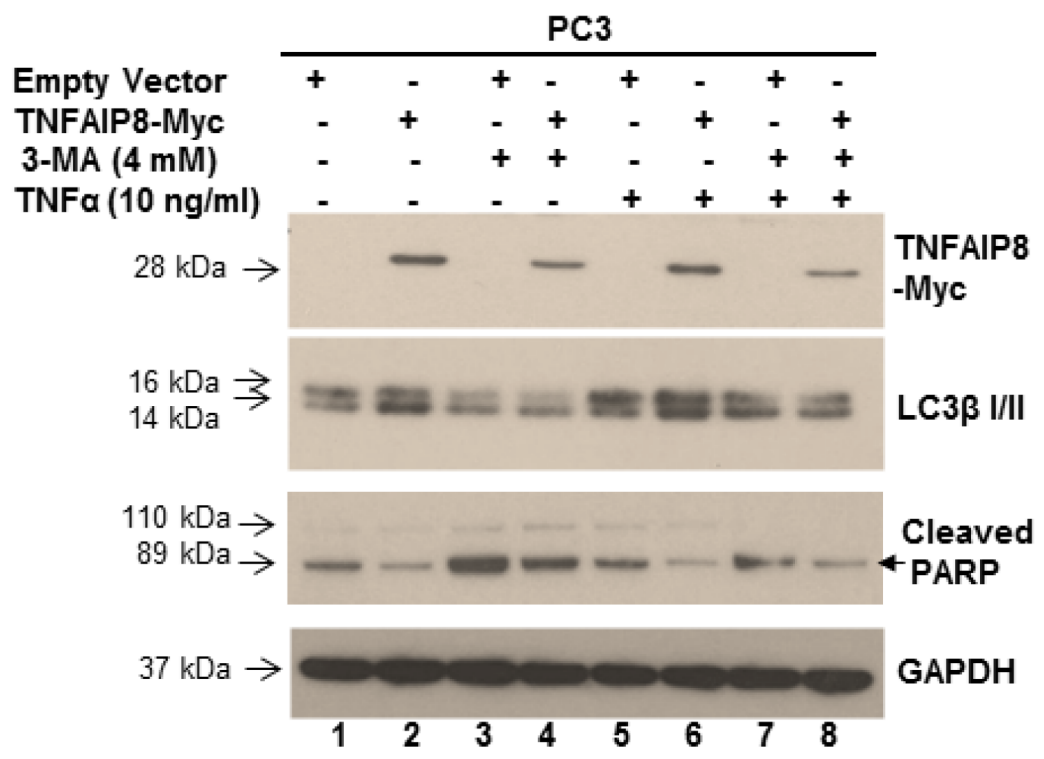

Figure 5: TNFAIP8 interacts with ATG3, induces autophagy, and inhibits apoptosis. (A) PC3 cell extracts (50 $\mu \mathrm{g})$ from empty vector- or TNFAIP8-Myc-transfected cells were immunoblotted with anti-Myc, anti-ATG3, and anti-GAPDH antibodies (input panel). (B) Cell lysates (1 mg) from empty vector- or TNFAIP8-Myc-transfected PC3 cells were immunoprecipitated with control IgG or anti-ATG3 antibody and immunoblotted with anti-TNFAIP8-Myc and anti-ATG3 antibody. LC- light-chain IgG, HC- heavy-chain IgG. (C) PC3 cells were transfected with empty vector or TNFAIP8-Myc plasmid and treated with 3-methyladenine (4 mM) and TNF $\alpha$ (10 ng/ml) for $24 \mathrm{~h}$ as indicated. Cell extracts $(50 \mu \mathrm{g})$ were immunoblotted with anti-Myc, anti-TNFAIP8, anti-LC3 $\beta$ I/II, anti-cleaved PARP, and anti-GAPDH antibodies. 
Knockdown of TNFAIP8 reduced the expression of LC3 $\beta$ I/II in breast cancer MCF7 cells (data not shown) and prostate cancer PC3 cells, which reinforces the role of TNFAIP8 in LC3 $\beta$ I/II regulation and autophagy.

Autophagy is a vital self-degradation process that eliminates damaged organelles and misfolded or aggregated proteins through the lysosomal degradation pathway [36-38]. Autophagy maintains normal cell homeostasis, and autophagic deregulation is associated with several pathological processes, including several cancers. Several reports have suggested that autophagy can affect chemotherapeutic and immunotherapeutic response in cancer cells $[39,40]$. Importantly, autophagy both positively and negatively regulates cell death, and recently, it has been shown that the response to death receptor activation is based on basal autophagy levels. In most tumor cells, TNFAIP8 has been reported to have a protective effect; however, TNFAIP8 promotes glucocorticoid-induced apoptosis in thymocytes [41]. Our data suggest that treatment with TNF $\alpha$ induced the expression of TNFAIP8 and the autophagy marker LC $3 \beta$ I/II. This induction led to inactivation of cellular apoptosis by decreasing the cleavage of apoptotic PARP and caspase-3, subsequently promoting cell survival (Figure 7). We also showed that TNFAIP8 increased resistance to the anticancer drugs, docetaxel, and doxorubicin, and promoted cell proliferation and cell growth in prostate cancer cells through the inactivation of cellular apoptosis and the induction of cellular autophagy. Previous studies showed that activation of cellular autophagy contributes to NED in prostate cancer cells $[33,34]$. Here, we demonstrated that TNFAIP8 expression induced expression of the NED biomarkers chromogranin A and synaptophysin in prostate cancer cells; however, the exact mechanism by which TNFAIP8 induces NED in prostate cancer cells remains unclear.

In conclusion, this study provides first-time evidence that TNFAIP8 protein participates in the initiation of cellular autophagy and modulates cell survival in prostate cancer cells. The role of TNFAIP8 in cell death or survival appears to depend on the cellular context. TNF $\alpha$ is a cytokine involved in systemic cellular inflammation, leading to cell death. Future studies should further investigate whether the level of TNFAIP8 expression induced by $\mathrm{TNF} \alpha$ determines cell fate by modulating autophagy-like events and if TNFAIP8 could act as a critical gatekeeper between cell survival and cell death.

\section{MATERIALS AND METHODS}

\section{Cell culture}

Cancer cell lines were obtained from Georgetown University Lombardi Comprehensive Cancer Center cell
A

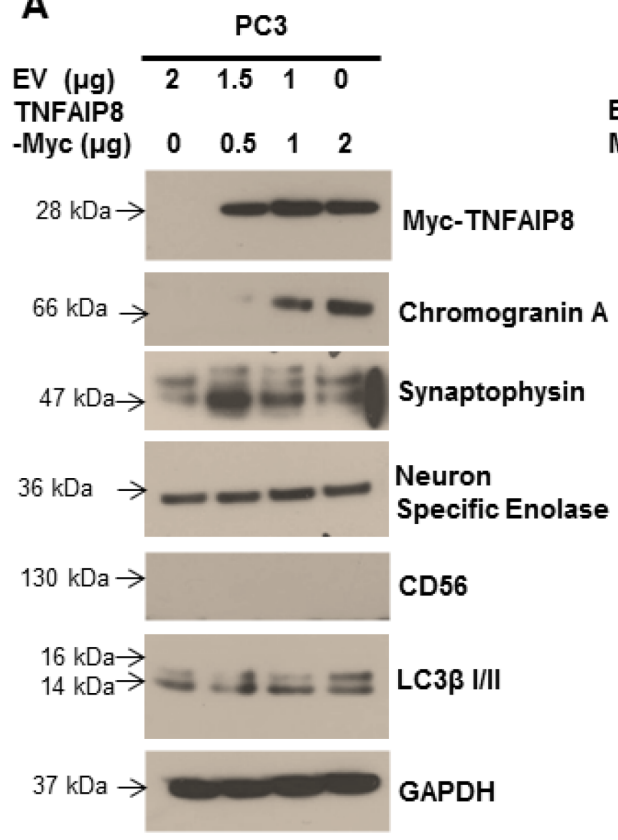

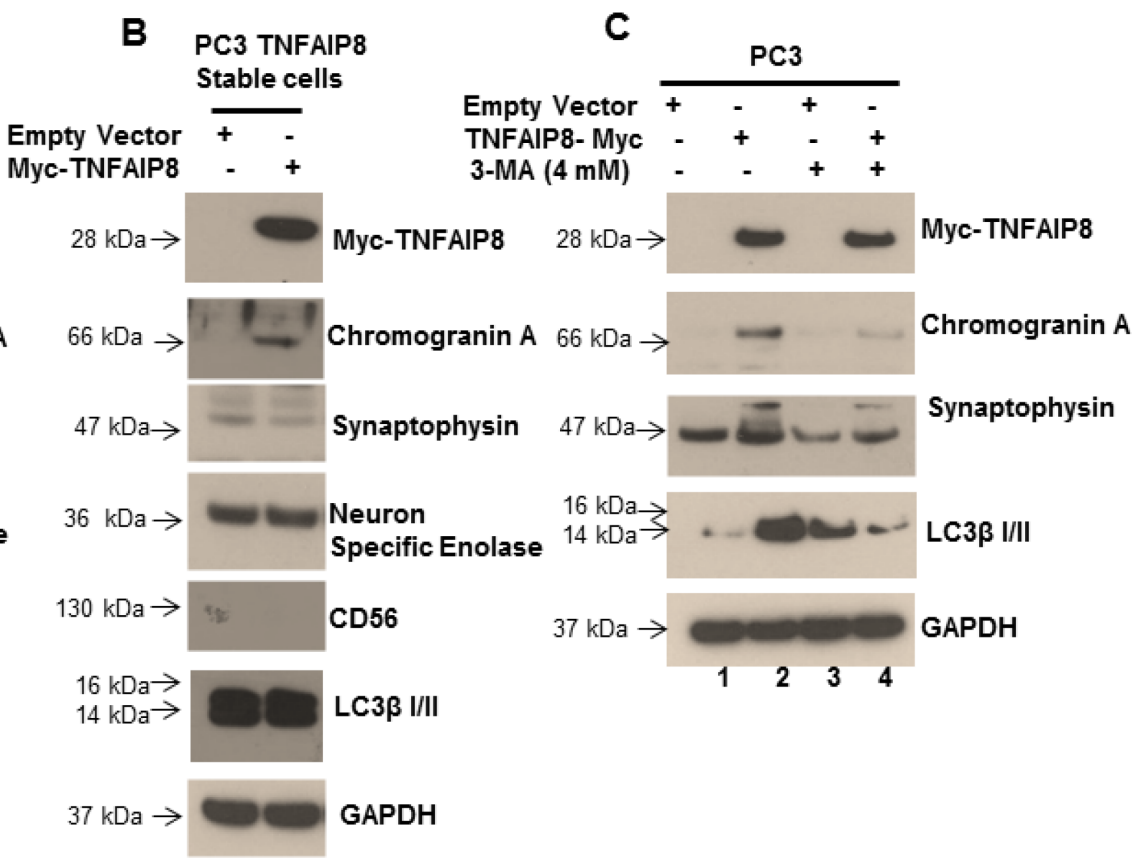

Figure 6: TNFAIP8 increases the expression of NED biomarkers in prostate cancer PC3 cells. (A) PC3 cells were transfected with empty vector or increasing amounts of TNFAIP8-Myc plasmid for $30 \mathrm{~h}$. The effect of TNFAIP8 protein expression on NED biomarkers, such as chromogranin A, synaptophysin, NSE, and NCAM-1/CD56, as well as the autophagy marker LC3 $\beta$ I/II was analyzed by immunoblotting. (B) Effect of stable TNFAIP8 expression on NED markers in PC3 cells. Cell extracts from PC3 cells stably expressing TNFAIP8 were analyzed by immunoblotting with the indicated antibodies. (C) PC3 cells were transfected with empty vector or TNFAIP8-Myc plasmid and treated with 3-methyladenine for $24 \mathrm{~h}$. The effect of TNFAIP8 expression, with and without 3-methyladenine, on the expression of NED and autophagy markers, was analyzed by immunoblotting. 
culture repository. Prostate cancer (LNCaP, PC3, C4-2) and breast cancer (MCF7 and MDA-MB-468) and liver cancer HepG2 cells were grown in appropriate medium (RPMI or DMEM from Invitrogen) containing 5-10\% Fetal Bovine Serum (FBS, Access Biologicals, Vista, CA, USA), $2 \mathrm{mM}$ glutamine, and $25 \mu \mathrm{g} / \mathrm{ml}$ gentamicin (Invitrogen) and incubated at $37^{\circ} \mathrm{C}$ with $5 \% \mathrm{CO}_{2}$. MCF7, MCF7-RAS, MCF7-ADR, MCF10A, MCF10A-Neo, MCF10A-RAS/ErbB2 and MCF10A-TGF $\alpha$ cells were also obtained from Georgetown University Lombardi Comprehensive Cancer Center cell culture repository and maintained as described previously [26-30]. Mouse Lewis lung carcinoma-1 (LLC-1) cells were obtained from Dr. Micheler Richardson's laboratory, and human monocytic leukemia THP-1 cells and human neuroblastoma SHSY5Y cells from Dr. K. Sean Kimbro's laboratory (BBRINorth Carolina Central University, NC). We also generated a stable PC3 cell line which expressed TNFAIP8-Myctagged protein. For this, PC3 cells were transfected with empty vector or TNFAIP8-Myc-tagged plasmid for $30 \mathrm{~h}$. Cells were trypsinized, re-plated, and treated with $600 \mu \mathrm{g} / \mathrm{ml} \mathrm{G} 418$ for 2 weeks. Antibiotic-containing medium was replaced every 3-4 days; cell colonies were selected, expanded, and maintained in presence of G418. TNFAIP8-Myc-tagged protein expression was confirmed by immunoblotting. All cell lines were grown at least $24 \mathrm{~h}$ and used for experiments once they reached $70-80 \%$ confluence.

\section{Western blot analysis}

Immunoblotting analysis was performed following standard procedures. Cells were lysed in cell lysis buffer (Cell Signaling, Danvers, MA, USA) containing protease inhibitor (Roche, Indianapolis, IN, USA). After centrifugation at $10,000 \mathrm{rpm}$ for $15 \mathrm{~min}$, the protein concentrations from the supernatants were estimated using a Bio-Rad protein assay (Bio-Rad, Hercules, CA, USA). The proteins $(30-50 \mu \mathrm{g})$ were separated on a NuPAGE 4-12\% Bis-Tris-SDS gel (Invitrogen) and transferred onto a PVDF membrane (Immobilon-P, Millipore, Billerica, MA, USA). Membranes were blocked in $1 \times$ blocking buffer (Sigma-Aldrich, St. Louis, MO, USA) for $1 \mathrm{~h}$ and incubated in primary antibody overnight at $4^{\circ} \mathrm{C}$. We used anti-TNFAIP8 antibody from Proteintech Group (Cat. \#15790-1-AP). Anti-CHK1, anti-cyclin B1, anti-cyclin A, anti-cyclin E2, anti-phospho-histone H3 (Ser10), anti-phospho-cdc2 (Tyr15), anti-phospho-Wee1(Ser642), anti-p21 (Waf1/Cip1), anti-Myt1, anti-LC3 $\beta$ I/II, anti4E-BP1, anti-SIRT1, anti-cleaved PARP, anti-caspase-3, anti-Myc tag, and anti-GAPDH antibodies were obtained from Cell Signaling Technology (Danvers, MA, USA). Anti-p27 and anti-Beclin1 were obtained from Santa Cruz Biotechnology (Dallas, TX, USA), anti-p62 from BD Bioscience (San Jose, CA, USA), and anti-ATG3 and anti- $\beta$-actin from Sigma. Prostate-cancer-specific NEDbiomarker antibodies, such as anti-synaptophysin, anti-

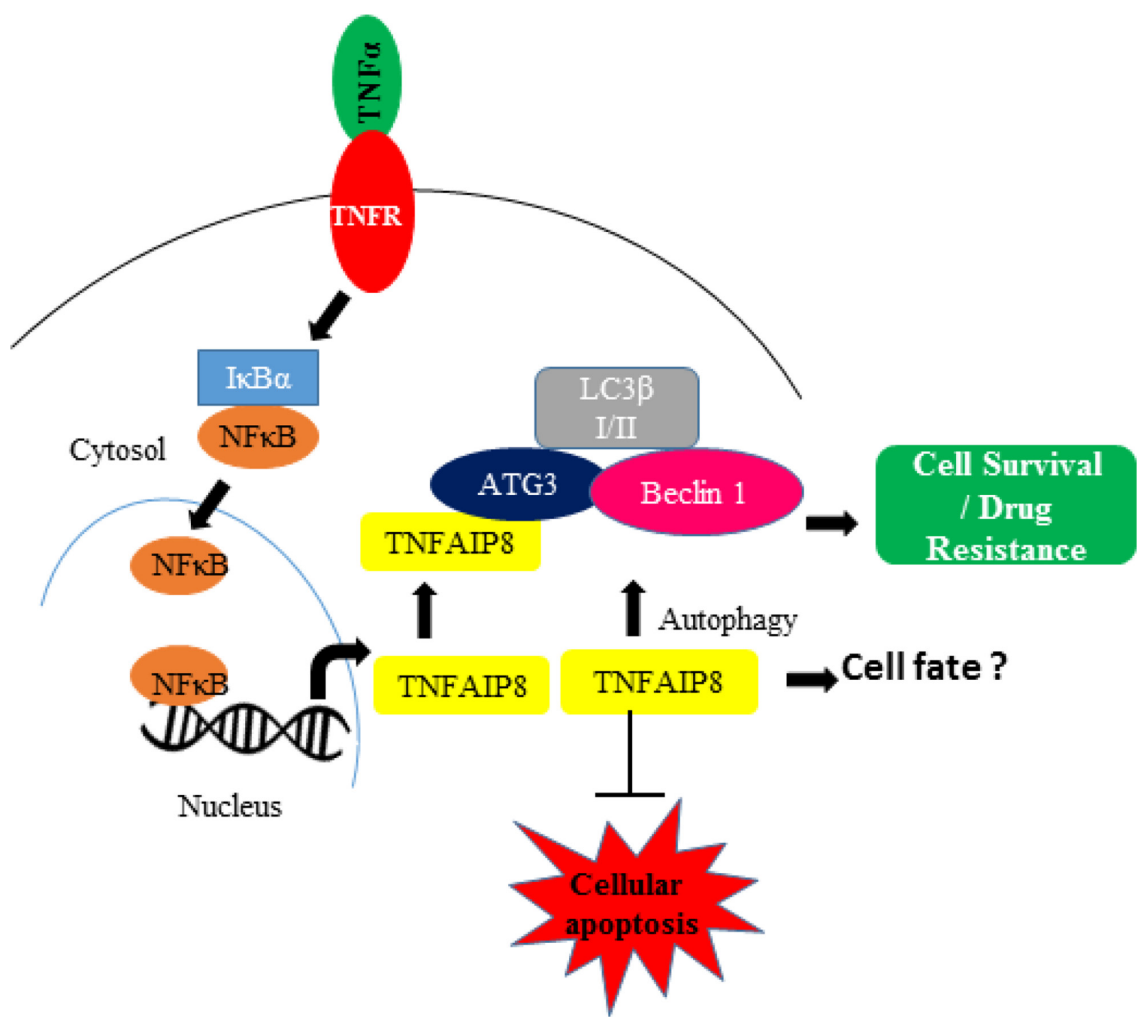

Figure 7: The involvement of the TNFAIP8 protein in autophagy. The model represents the expression and involvement of TNFAIP8 in autophagy formation. The model also indicates the important role of TNFAIP8 in determining cell fate during TNF $\alpha$ signaling. 
NSE, anti-chromogranin A, and anti-NCAM-1/CD56 were purchased from Novus Biologicals (Littleton, CO, USA). All antibodies were used according to the manufacturer $>\mathrm{S}$ suggestions. After washing the membranes three times with Tris-buffered saline with $0.1 \%$ Tween 20 (TBST), the membranes were incubated in appropriate secondary antibody (1:10000 dilution) (Jackson ImmunoResearch, PA) for $1 \mathrm{~h}$ at room temperature, and immunoreactive bands were visualized using ECL chemiluminescence detection (Signagen Laboratories, Rockville, MD, USA).

\section{Immunoprecipitation}

Cell extracts $(1 \mathrm{mg}$ ) from empty-vector transfected or TNFAIP8-Myc-transfected PC3 cells were equilibrated in radioimmunoprecipitation assay buffer (RIPA; $50 \mathrm{~mm}$ Tris pH 8.0, 150 mM NaCl, 0.2 mM EDTA, 1\% Nonidet P-40, and $1 \mathrm{mM}$ phenylmethylsulfonyl fluoride, supplemented with protease inhibitor [Roche Applied Science]). The lysates were cleared with protein AG plus-agarose beads (Santa Cruz Biotechnology) and incubated with $1 \mu \mathrm{g}$ of anti-ATG3 antibody (Sigma) or with control rabbit IgG (Santa Cruz Biotechnology) at $4^{\circ} \mathrm{C}$ overnight. Immune complexes were collected by adding $20 \mu \mathrm{l}$ of protein AGagarose beads equilibrated with lysis buffer. The immune complexes were washed three times with RIPA buffer, and proteins were resolved on a $4-12 \%$ Bis-Tris SDSPAGE gel and transferred onto a PVDF membrane. The membranes were blocked with $1 \times$ blocking buffer and incubated with their respective primary (1:1000 dilution) and secondary antibodies (1:10000 dilution) as described above. Immunoreactive bands were visualized using a chemiluminescence system ECL.

\section{Microarray profiling}

PC3 cells were transiently transfected with empty vector or TNFAIP8, and RNA was isolated using the RNeasy Mini Kit (QIAGEN) according to the manufacturer's instructions. The total RNA was pooled from three independent biological replicates. RNA concentration and purity (OD $260 \mathrm{~nm} / 280 \mathrm{~nm}$ ) were measured using a NanoDrop ND-1000 spectrophotometer (Thermo Fisher), and the RNA integrity number was determined using an Agilent 2100 Bioanalyzer Instrument (Agilent, Santa Clara, CA, USA). Gene expression profiling was performed using an Illumina HumanHT-12 v4 Expression BeadChip platform containing 47,000 probes that covered RefSeq and Unigene annotated genes (Illumina). Biotinylated cRNA was generated by labeling 500 ng total RNA using the Illumina TotalPrep-96 RNA Amplification Kit (Ambion) following the manufacturers' instructions. Purified cRNA was quantified, and the fragment size was determined using an Agilent 2100 Bioanalyzer. Approximately 750 ng of biotinylated cRNA probe was hybridized overnight to the Illumina HumanHT-12 v4 Expression BeadChip.
The chip was washed and scanned according to the manufacturer's instructions. The BeadChips were scanned using a HiScanSQ System (Illumina Inc., San Diego, CA, USA). Microarray images were registered and extracted automatically during the scan using the manufacturer's default settings. The array data were submitted to Array Express with accession number E-MTAB-6803.

\section{RNA isolation, cDNA Synthesis, and qPCR}

PC3 cells were plated in 6-well plates at a density of $1 \times 10^{5}$ cells/wells $24 \mathrm{~h}$ before transfection. Cells were transfected with $2 \mu \mathrm{g}$ of empty pcDNA3.1 vector or TNFAIP8-Myc tagged plasmid DNA using lipofectamine-2000 transfection reagent (Invitrogen) according to the manufacturer's instructions. After $30 \mathrm{~h}$ of transfection, cells were harvested, and total RNA was isolated using the TRIZOL Reagent (Invitrogen, Carlsbad, CA, USA). RNA ( $1 \mu \mathrm{g}$ ) was reverse transcribed using a High Capacity cDNA Reverse Transcription kit (Applied Biosystems). cDNA was mixed with the Power SYBR Green PCR master mix (Applied Biosystems, Carlsbad, CA, USA) with both forward and reverse primers of TNFAIP8 and other cell cycle-related genes as indicated in (Supplementary Table 1). GAPDH was amplified as an internal control. The PCR mixtures were run on a QuantStudio 3 PCR System (Applied Biosystems) using relative quantitation according to the manufacturer's protocols.

\section{RT-PCR}

Total RNA from PC3, MDA-MB-468, LNCaP, LLC1, THP-1, and SH-SY5Y cells were isolated using TRIzol reagent (Invitrogen). RNA ( $1 \mu \mathrm{g})$ was reverse transcribed using a High Capacity cDNA Reverse Transcription kit (Applied Biosystems). The expression of the five TNFAIP8 isoforms was analyzed using GoTaq ${ }^{\circledR}$ Green PCR Master Mix (Promega). The following isoform-specific forward primers were used; Isoform 1: 5'-CGAGTACATGTGAGCGGTAAT-3', Isoform 2: 5'-AC CGAGAGAGCAGAGAACT-3', Isoform 3: 5'-GGCTGT CCGGCTTCTTTAT-3', Isoform 4: 5'- AGTCCATCCC TGTTGTGAATG-3', Isoform 5: 5'-AAGTGCAGTGG TGAGATCATAG-3'. We used a common reverse primer: 5'-GATCTTCTCTGCCTCCTTCTTG-3' (Figure 1A and Supplementary Figure 1A). PCR parameters were: 2 min denaturation at $95^{\circ} \mathrm{C} ; 30$ cycles of $95^{\circ} \mathrm{C}$ for $30 \mathrm{sec}, 58^{\circ} \mathrm{C}$ for $30 \mathrm{sec}$, and $72^{\circ} \mathrm{C}$ for $40 \mathrm{sec}$; and a final extension at $72^{\circ} \mathrm{C}$ for $5 \mathrm{~min}$. PCR was performed using a SimpliAmp thermal cycler (Applied Biosystem). The PCR products were electrophoresed on a $1.5 \%$ agarose gel, and gels were stained with ethidium bromide. The PCR-amplified bands were extracted from the agarose gel and sequenced to identify the isoforms. 


\section{Plasmids and siRNA transfections}

A human tumor necrosis factor alpha-induced protein 8, transcript variant 1 (TNFAIP8)-Myc-DDK-tagged ORF cDNA plasmid was obtained from Origene (RockvilleMD, Cat \# RC202729). The plasmid encodes 198 amino acids of TNFAIP8 protein (isoform 1 or 3), with Myc tag (EQKLISEEDL), and a FLAG tag (DYKDDDDK). For transfection, $\mathrm{PC} 3, \mathrm{LNCaP}$, and $\mathrm{C} 4-2$ prostate cancer cells were plated in 6-well plates at a density of $1 \times 10^{5}$ cells/ wells $24 \mathrm{~h}$ before transfection. Cells were transfected with 2-4 $\mu$ g of empty pcDNA3.1 vector or TNFAIP8Myc tagged plasmid DNA using lipofectamine-2000 transfection reagent (Invitrogen) according to the manufacturer's instructions. After 24-30 h of transfection, cells were harvested, and the expression of theTNFAIP8Myc tagged protein was examined by immunoblotting. For siRNA transfection, we used to control and TNFAIP8 human siRNA purchased from Dharmacon (Lafayette, $\mathrm{CO})$. PC3 cells were transfected with $100 \mathrm{nM}$ control or TNFAIP8 siRNA using Lipofectamine RNAiMAX reagent (Invitrogen) according to the manufacturer's instructions. Following $30 \mathrm{~h}$ of transfection, cells were harvested and TNFAIP8 knockdown was confirmed by Western blotting using anti-TNFAIP8 antibody. Anti-GAPDH antibody was used as the control.

\section{Immunofluorescence}

The EGFP-LC3B plasmid was obtained from Addgene (plasmid id-11546). PC3 cells $\left(1 \times 10^{5}\right)$ were grown on coverslips in 6-well plates for $24 \mathrm{~h}$ and cotransfected with $2 \mu \mathrm{g}$ of empty vector (pcDNA3.1) and EGFP-LC3B or TNFAIP8-Myc-tagged plasmid and EGFP-LC3B. The cells were simultaneously treated with $10 \mathrm{ng} / \mathrm{ml} \mathrm{TNF} \alpha$ (Invitrogen) and 3-methyladenine (4 mM) (Sigma) as indicated for $24 \mathrm{~h}$. Cells were washed with PBS and fixed with $4 \%$ paraformaldehyde for $15 \mathrm{~min}$. Cells were permeabilized with $0.25 \%$ Triton X-100 in blocking buffer (1\% goat serum (Sigma) in PBS). Cells were washed twice with PBS and incubated with 1:500 dilutions of anti-Myc rabbit antibody in blocking buffer at $4^{\circ} \mathrm{C}$ for $18 \mathrm{~h}$. Then, cells were washed twice with PBS and incubated with an Alexa-Fluor-568-conjugated antirabbit antibody (Invitrogen). Following immunostaining, cells were washed twice with PBS and mounted with Vectashield mounting medium (Vector Lab.) containing nuclear DAPI stain. Cells were imaged using an OlympusBX60 fluorescent microscope. The number of GFP-LC3B-related puncta formed in the cells $(n=10)$ was counted and plotted.

\section{TNF $\alpha$ and drug treatments}

PC3, LNCaP, and C4-2 cells were grown in RPMI medium for $24 \mathrm{~h}$ to $70-80 \%$ confluency. The cells were treated with $10 \mathrm{ng} / \mathrm{ml}$ of $\mathrm{TNF} \alpha$ for the indicated time periods, and the TNFAIP8 expression was analyzed by immunoblotting. For drug treatments, cells were treated with DMSO (control) or the indicated concentrations of doxorubicin (Fisher Scientific) and docetaxel (Selleckchem, Houston, TX, USA) for $24 \mathrm{~h}$. Colony formation assays were performed as described below.

\section{Colony formation and cell proliferation}

PC3, LNCaP, and C4-2 cells were grown in RPMI medium and transfected with TNFAIP8-Myc plasmid or pcDNA3.1 empty vector ( $2 \mu \mathrm{g} /$ well in 6-well plates) for $24 \mathrm{~h}$. After $24 \mathrm{~h}$ of transfection, cells were trypsinized and counted. Live cells were re-plated in 6-well plates (2000 cells/well) in triplicate and allowed to grow for 7-10 days. Cells were fixed with cold methanol and stained with $0.1 \%$ crystal violet for $30 \mathrm{~min}$. Cells were washed with distilled water and allowed to dry. Blue colonies were counted and plotted. Cell proliferation was performed in 96well plates using the WST-1 assay. PC3, LNCaP, and C4-2 cells were transfected with the TNFAIP8-Myc plasmid or empty vector for $18 \mathrm{~h}$ and treated with $0.5 \mathrm{nM}$ of docetaxel or $1 \mu \mathrm{M}$ doxorubicin for $24 \mathrm{~h}$. Then, cells were trypsinized and counted. Live cells were re-plated in 96-well plates $\left(1 \times 10^{4}\right.$ cells/well $)$ and incubated for $48 \mathrm{~h}$. Cell proliferation was measured by adding $10 \mu \mathrm{WST}-1$ reagent according to manufacturer's instructions (Roche Applied Science, Indianapolis, IN, USA). Cell proliferation was measured at $450 \mathrm{~nm}$ using Fluostar Omega plate reader (BMG Lab tech, Cary, NC, USA).

\section{Statistical analysis}

The data from cell colony formation and cell proliferation were analyzed using a two-tailed Student's $t$-test. Data are expressed as the mean \pm standard deviation (S.D.). $p$ values are shown in figures.

\section{Author contributions}

SN and MR planned, designed, and performed the experiments and wrote the manuscript. HK, DP, JL, HM, SS, and SC analyzed the data SSN, a Catonsville high school student, was also involved in performing the experiments. DK supervised, planned, and designed the research and wrote the manuscript.

\section{CONFLICTS OF INTEREST}

The authors declare that they have no conflicts of interest. 


\section{GRANT SUPPORT}

We gratefully acknowledge the grants U01CA194730, U54MD012392, R01MD012767, from the National Institutes of Health to DK.

\section{REFERENCES}

1. Patel S, Wang FH, Whiteside TL, Kasid U. Identification of seven differentially displayed transcripts in human primary and matched metastatic head and neck squamous cell carcinoma cell lines: implications in metastasis and/or radiation response. Oral Oncol. 1997; 33:197-203.

2. Horrevoets AJ, Fontijn RD, van Zonneveld AJ, de Vries CJ, ten Cate JW, Pannekoek H. Vascular endothelial genes that are responsive to tumor necrosis factor-alpha in vitro are expressed in atherosclerotic lesions, including inhibitor of apoptosis protein-1, stannin, and two novel genes. Blood. 1999; 93:3418-31.

3. Freundt EC, Bidere N, Lenardo MJ. A different TIPE of immune homeostasis. Cell. 2008; 133:401-2. https://doi. org/10.1016/j.cell.2008.04.017.

4. Kumar D, Whiteside TL, Kasid U. Identification of a novel tumor necrosis factor-alpha-inducible gene, SCCS2, containing the consensus sequence of a death effector domain of fas-associated death domain-like interleukinlbeta-converting enzyme-inhibitory protein. J Biol Chem. 2000; 275:2973-8.

5. Sun H, Gong S, Carmody RJ, Hilliard A, Li L, Sun J, Kong L, Xu L, Hilliard B, Hu S, Shen H, Yang X, Chen YH. TIPE2, a negative regulator of innate and adaptive immunity that maintains immune homeostasis. Cell. 2008; 133:415-26. https://doi.org/10.1016/j.cell.2008.03.026.

6. Kumar D, Gokhale P, Broustas C, Chakravarty D, Ahmad I, Kasid U. Expression of SCC-S2, an antiapoptotic molecule, correlates with enhanced proliferation and tumorigenicity of MDA-MB 435 cells. Oncogene. 2004; 23:612-6. https:// doi.org/10.1038/sj.onc.1207123.

7. Zhang S, Zhang Y, Wei X, Zhen J, Wang Z, Li M, Miao W, Ding H, Du P, Zhang W, He M, Yi F. Expression and regulation of a novel identified TNFAIP8 family is associated with diabetic nephropathy. Biochim Biophys Acta. 2010; 1802:1078-86. https://doi.org/10.1016/j.bbadis.2010.08.003.

8. Cao X, Zhang L, Shi Y, Sun Y, Dai S, Guo C, Zhu F, Wang Q, Wang J, Wang X, Chen YH, Zhang L. Human tumor necrosis factor (TNF)-alpha-induced protein 8-like 2 suppresses hepatocellular carcinoma metastasis through inhibiting Rac1. Mol Cancer. 2013; 12:149. https://doi. org/10.1186/1476-4598-12-149.

9. Li Y, Jing C, Chen Y, Wang J, Zhou M, Liu X, Sun D, Mu L, Li L, Guo X. Expression of tumor necrosis factor alphainduced protein 8 is upregulated in human gastric cancer and regulates cell proliferation, invasion and migration. Mol Med Rep. 2015; 12:2636-42. https://doi.org/10.3892/ mmr.2015.3690.
10. Liu T, Xia B, Lu Y, Xu Y, Lou G. TNFAIP8 overexpression is associated with platinum resistance in epithelial ovarian cancers with optimal cytoreduction. Hum Pathol. 2014; 45:1251-7. https://doi.org/10.1016/j.humpath.2014.02.005.

11. Zhang Y, Wang MY, He J, Wang JC, Yang YJ, Jin L, Chen ZY, Ma XJ, Sun MH, Xia KQ, Hong XN, Wei QY, Zhou XY. Tumor necrosis factor-alpha induced protein 8 polymorphism and risk of non-Hodgkin's lymphoma in a Chinese population: a case-control study. PLoS One. 2012; 7:e37846. https://doi.org/10.1371/journal.pone.0037846.

12. Day TF, Mewani RR, Starr J, Li X, Chakravarty D, Ressom H, Zou X, Eidelman O, Pollard HB, Srivastava M, Kasid UN. Transcriptome and Proteome Analyses of TNFAIP8 Knockdown Cancer Cells Reveal New Insights into Molecular Determinants of Cell Survival and Tumor Progression. Methods Mol Biol. 2017; 1513:83-100. https:// doi.org/10.1007/978-1-4939-6539-7_7.

13. Lowe JM, Nguyen TA, Grimm SA, Gabor KA, Peddada SD, Li L, Anderson CW, Resnick MA, Menendez D, Fessler MB. The novel p53 target TNFAIP8 variant 2 is increased in cancer and offsets p53-dependent tumor suppression. Cell Death Differ. 2017; 24:181-91. https:// doi.org/10.1038/cdd.2016.130.

14. Sun H, Lou Y, Porturas T, Morrissey S, Luo G, Qi J, Ruan Q, Shi S, Chen YH. Exacerbated experimental colitis in TNFAIP8-deficient mice. J Immunol. 2015; 194:5736-42. https://doi.org/10.4049/jimmunol.1401986.

15. Porturas TP, Sun H, Buchlis G, Lou Y, Liang X, Cathopoulis T, Fayngerts S, Johnson DS, Wang Z, Chen YH. Crucial roles of TNFAIP8 protein in regulating apoptosis and Listeria infection. J Immunol. 2015; 194:5743-50. https://doi.org/10.4049/jimmunol.1401987.

16. Chittaranjan S, Xu J, Kuzyk M, Dullat HK, Wilton J, DeVorkin L, Lebovitz C, Morin GB, Marra MA, Gorski SM. The Drosophila TIPE family member Sigmar interacts with the Ste20-like kinase Misshapen and modulates JNK signaling, cytoskeletal remodeling and autophagy. Biol Open. 2015; 4:672-84. https://doi.org/10.1242/bio.20148417.

17. Ha JY, Kim JS, Kang YH, Bok E, Kim YS, Son JH. Tnfaip8 11/Oxi-beta binds to FBXW5, increasing autophagy through activation of TSC2 in a Parkinson's disease model. J Neurochem. 2014; 129:527-38. https://doi.org/10.1111/jnc.12643.

18. Filippi-Chiela EC, Thome MP, Bueno e Silva MM, Pelegrini AL, Ledur PF, Garicochea B, Zamin LL, Lenz G. Resveratrol abrogates the temozolomide-induced G2 arrest leading to mitotic catastrophe and reinforces the temozolomide-induced senescence in glioma cells. BMC Cancer. 2013; 13:147. https://doi.org/10.1186/1471-2407-13-147.

19. Pathania AS, Guru SK, Kumar S, Kumar A, Ahmad M, Bhushan S, Sharma PR, Mahajan P, Shah BA, Sharma S, Nargotra A, Vishwakarma R, Korkaya H, et al. Interplay between cell cycle and autophagy induced by boswellic acid analog. Sci Rep. 2016; 6:33146. https://doi.org/10.1038/ srep33146. 
20. Rusten TE, Stenmark H. p62, an autophagy hero or culprit? Nat Cell Biol. 2010; 12:207-9. https://doi.org/10.1038/ ncb0310-207.

21. Huang R, Xu Y, Wan W, Shou X, Qian J, You Z, Liu B, Chang C, Zhou T, Lippincott-Schwartz J, Liu W. Deacetylation of nuclear LC3 drives autophagy initiation under starvation. Mol Cell. 2015; 57:456-66. https://doi. org/10.1016/j.molcel.2014.12.013.

22. Ramalinga M, Roy A, Srivastava A, Bhattarai A, Harish V, Suy S, Collins S, Kumar D. MicroRNA-212 negatively regulates starvation induced autophagy in prostate cancer cells by inhibiting SIRT1 and is a modulator of angiogenesis and cellular senescence. Oncotarget. 2015; 6:34446-57. https://doi.org/10.18632/oncotarget.5920.

23. Cha HH, Hwang JR, Kim HY, Choi SJ, Oh SY, Roh CR. Autophagy induced by tumor necrosis factor alpha mediates intrinsic apoptosis in trophoblastic cells. Reprod Sci. 2014; 21:612-22. https://doi.org/10.1177/1933719113508816.

24. Opperman CM, Sishi BJ. Tumor necrosis factor alpha stimulates p62 accumulation and enhances proteasome activity independently of ROS. Cell Biol Toxicol. 2015; 31:83-94. https://doi.org/10.1007/s10565-015-9295-8.

25. Ye YC, Yu L, Wang HJ, Tashiro S, Onodera S, Ikejima T. TNFalpha-induced necroptosis and autophagy via supression of the p38-NF-kappaB survival pathway in L929 cells. J Pharmacol Sci. 2011; 117:160-9.

26. Ciardiello F, Gottardis M, Basolo F, Pepe S, Normanno N, Dickson RB, Bianco AR, Salomon DS. Additive effects of c-erbB-2, c-Ha-ras, and transforming growth factoralpha genes on in vitro transformation of human mammary epithelial cells. Mol Carcinog. 1992; 6:43-52.

27. Ciardiello F, Kim N, McGeady ML, Liscia DS, Saeki T, Bianco C, Salomon DS. Expression of transforming growth factor alpha (TGF alpha) in breast cancer. Ann Oncol. 1991; 2:169-82.

28. Guo-Chang F, Chu-Tse W. Transfer of p14ARF gene in drug-resistant human breast cancer MCF-7/Adr cells inhibits proliferation and reduces doxorubicin resistance. Cancer Lett. 2000; 158:203-10.

29. Ochieng J, Basolo F, Albini A, Melchiori A, Watanabe H, Elliott J, Raz A, Parodi S, Russo J. Increased invasive, chemotactic and locomotive abilities of c-Ha-ras-transformed human breast epithelial cells. Invasion Metastasis. 1991; $11: 38-47$.

30. Screpanti I, Felli MP, Toniato E, Meco D, Martinotti S, Frati L, Santoni A, Gulino A. Enhancement of natural-killercell susceptibility of human breast-cancer cells by estradiol and v-Ha-ras oncogene. Int J Cancer. 1991; 47:445-9.

31. Monastyrska I, Rieter E, Klionsky DJ, Reggiori F. Multiple roles of the cytoskeleton in autophagy. Biol
Rev Camb Philos Soc. 2009; 84:431-48. https://doi. org/10.1111/j.1469-185X.2009.00082.x.

32. Kristensen AR, Gsponer J, Foster LJ. A high-throughput approach for measuring temporal changes in the interactome. Nat Methods. 2012; 9:907-9. https://doi.org/10.1038/ nmeth.2131.

33. Chang PC, Wang TY, Chang YT, Chu CY, Lee CL, Hsu HW, Zhou TA, Wu Z, Kim RH, Desai SJ, Liu S, Kung HJ. Autophagy pathway is required for IL-6 induced neuroendocrine differentiation and chemoresistance of prostate cancer LNCaP cells. PLoS One. 2014; 9:e88556. https://doi.org/10.1371/journal.pone.0088556.

34. Lin TP, Chang YT, Lee SY, Campbell M, Wang TC, Shen SH, Chung HJ, Chang YH, Chiu AW, Pan CC, Lin CH, Chu CY, Kung HJ, et al. REST reduction is essential for hypoxiainduced neuroendocrine differentiation of prostate cancer cells by activating autophagy signaling. Oncotarget. 2016; 7:26137-51. https://doi.org/10.18632/oncotarget.8433.

35. Zhang LJ, Liu X, Gafken PR, Kioussi C, Leid M. A chicken ovalbumin upstream promoter transcription factor I (COUPTFI) complex represses expression of the gene encoding tumor necrosis factor alpha-induced protein 8 (TNFAIP8). J Biol Chem. 2009; 284:6156-68. https://doi.org/10.1074/ jbc.M807713200.

36. Levine B, Kroemer G. Autophagy in the pathogenesis of disease. Cell. 2008; 132:27-42. https://doi.org/10.1016/j. cell.2007.12.018.

37. Galluzzi L, Pietrocola F, Levine B, Kroemer G. Metabolic control of autophagy. Cell. 2014; 159:1263-76. https://doi. org/10.1016/j.cell.2014.11.006.

38. Guo JY, Xia B, White E. Autophagy-mediated tumor promotion. Cell. 2013; 155:1216-9. https://doi.org/10.1016/j. cell.2013.11.019.

39. Gump JM, Staskiewicz L, Morgan MJ, Bamberg A, Riches DW, Thorburn A. Autophagy variation within a cell population determines cell fate through selective degradation of Fap-1. Nat Cell Biol. 2014; 16:47-54. https://doi.org/10.1038/ncb2886.

40. Wei Y, Zou Z, Becker N, Anderson M, Sumpter R, Xiao G, Kinch L, Koduru P, Christudass CS, Veltri RW, Grishin NV, Peyton M, Minna J, et al. EGFR-mediated Beclin 1 phosphorylation in autophagy suppression, tumor progression, and tumor chemoresistance. Cell. 2013; 154:1269-84. https://doi.org/10.1016/j.cell.2013.08.015.

41. Woodward MJ, de Boer J, Heidorn S, Hubank M, Kioussis D, Williams O, Brady HJ. Tnfaip8 is an essential gene for the regulation of glucocorticoid-mediated apoptosis of thymocytes. Cell Death Differ. 2010; 17:316-23. https:// doi.org/10.1038/cdd.2009.125. 